\title{
Study on Supporting Structure Performance of Deep Soft Soil Foundation Pit near Sea under Waves, Tides, Vibration, and Unbalanced Loads
}

\author{
Junsheng Chen, ${ }^{1,2}$ Chen Lin, ${ }^{1}$ Shuzhuo Liu $\mathbb{B D}^{1,2}$ and Haihong Mo ${ }^{1}$ \\ ${ }^{1}$ State Key Laboratory of Subtropical Building Science, School of Civil Engineering and Transportation, \\ South China University of Technology, Guangzhou 510640, China \\ ${ }^{2}$ South China Institute of Geotechnical Engineering, South China University of Technology, Guangzhou 510640, China
}

Correspondence should be addressed to Shuzhuo Liu; 664368480@qq.com

Received 19 March 2020; Revised 16 June 2020; Accepted 23 July 2020; Published 8 August 2020

Academic Editor: Filippo Ubertini

Copyright ( $\odot 2020$ Junsheng Chen et al. This is an open access article distributed under the Creative Commons Attribution License, which permits unrestricted use, distribution, and reproduction in any medium, provided the original work is properly cited.

In addition to the vibration loads caused by offshore structure construction, the offshore foundation pit can also be affected by additional hydraulic loads such as waves, tides, and typhoons, hindering our understanding of the mechanical performance of the foundation pit supporting structure. In order to illuminate this mechanical performance under waves, tides, hammering, and unbalanced loads, this paper analyzed the supporting structure with theoretical and numerical simulations. The results were verified with field monitoring data. Moreover, the influences of loads, including construction vibration loads and unbalanced loads, on structure and soil were discussed. By applying these results to the engineering design, this research could provide a reference for studying mechanical properties of relevant supporting structures and the construction of offshore foundation pits.

\section{Introduction}

An increasing number of cross-sea tunnels, bridges [1], large-scale wharves, offshore wind turbine structures [2-6], and other major projects have been constructed near seashores, indicating the necessity of more offshore foundation pits. Unlike the traditional foundation pits on land far from the sea $[7,8]$, an offshore foundation pit owns many unique characteristics, such as poor soil quality [9], additional hydraulic loads including waves, tides, and typhoons, and other extreme weather effects. Also, there may be other offshore structures nearby or around the offshore foundation pit, imposing additional vibration loads. Considering these unfavorable factors, a study of the specific influence of additional hydraulic and construction vibration loads on structure and soil may help improve the engineering technology of foundation pit support by referring to relevant engineering problems and scientific issues. Therefore, it is of engineering and scientific significance to study the supporting technology of soft soil foundation pits in coastal areas under adverse conditions such as waves, tidal forces, vibration loads, and extreme weather.

Many researchers have studied the construction of foundation pits in coastal soft soil strata. Li et al. [10] used MATLAB to determine the spatiotemporal evolution of the deep foundation pit seepage field and the coastal seepage field evolution model and then analyzed the influence of seepage field on the foundation pit supporting structure in the excavation process through numerical simulations. Qin et al. [11] studied three special supporting methods adopted in the coastal foundation pit construction, and they effectively solved the challenges in a coastal soft soil region, i.e., the high ground water level, low inner friction angle, and cohesion. Yang et al. [12] studied the design and construction of the linked piles in deep foundation pits in a coastal area of Fujian Province, which provided a valuable reference.

In terms of the influence of waves and other hydrodynamic effects on foundation pits, Zhang and Xiao [13] derived an analytical solution for the excess pore water 
pressure response in the basal clay based on a large excavation model. Hong and $\mathrm{Ng}$ [14] and Hong et al. [15] systematically revealed the plastic failure mechanisms of excavations associated with hydraulic uplift, through a comprehensive program of centrifuge model tests and finite element analyses considering various geometries and soil properties. Barros and Santos [16] proposed a numerical procedure based on the boundary element method and the trail wedge method to obtain the pore water pressure and the active Earth pressure coefficients with seepage. Ying et al. [17] studied the response of excess pore water pressure around a clay silt foundation pit under wave action by model tests and obtained the rule of excess pore pressure around the offshore foundation pit.

From the existing research, researchers have drawn many conclusions about the influence of additional hydraulic loads such as waves and foundation pit construction loads on structure and soil in the coastal soft soil areas [18-20]. However, there are limited studies on the foundation pit in coastal areas under the simultaneous action of waves, tides, and vibration loads. This paper aims to provide guidance to the relevant research.

Due to the additional hydraulic loads, such as waves, tides, and typhoons, as well as the vibration loads caused by the construction of adjacent wharves, there are many problems in constructing foundation pits. Based on a foundation pit project in Nansha District, Guangzhou City, Guangdong Province, China, this paper studied the mechanical properties of the foundation pit supporting structure under dynamic loads such as waves, tides, hammering, and unbalanced loads and applied the research results to the engineering design of this project. During the construction process, the lateral displacement of the diaphragm wall was monitored on site. Based on the theory and numerical analysis, the specific mechanism by which additional hydraulic loads and construction vibration loads influence the structure and soil was clarified, providing a reference for the foundation pit supporting engineering in deep, soft soil areas of an offshore wharf. The study intends to promote the further development of relevant research on the influence of waves, tides, and vibration and unbalanced loads on supporting structures and soil.

\section{General Situation of Engineering}

The study pit is located in Nansha District, Guangzhou City, Guangdong Province, China, on the West Bank of Lingding Ocean at the Pearl River Estuary. The foundation pit site is located near Humen Bridge, south of Harbor Front Avenue in the west, and north of Harbor Front Avenue in the north. Passenger Port Station of Metro Line 4 Extension Line is located in the south of the foundation pit. After the completion of the project, two drainage cruise ships, 100,000 tons and 225,000 tons, respectively, will be berthed on the east side with good water transport conditions. The location of the foundation pit is shown in Figure 1.

The total area of the foundation pit is about $55494.9 \mathrm{~m}^{2}$ and the depth is about $10 \mathrm{~m}$. The Ministry of Construction of China defines the excavation of a foundation pit with a depth

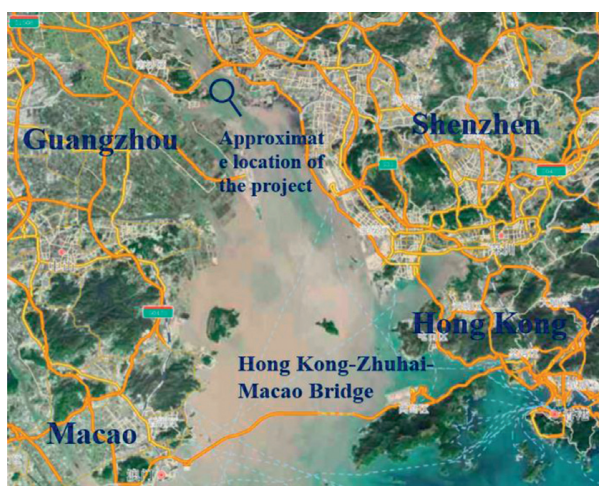

FIgURE 1: Location of the foundation pit of Nansha International Cruise Terminal Complex.

of more than $5 \mathrm{~m}$ (including $5 \mathrm{~m}$ ) as a deep foundation pit. Therefore, it is a deep foundation pit project. In this project, the coastal wharf will be reconstructed. The original wharf along the front edge of the new wharf will move $50 \mathrm{~m}$ to the coastal side, whose renovation scheme is shown in Figure 2. The supporting structure of the foundation pit on the coastal side of the project will be constructed based on the original wharf. The elevation of municipal roads is about $6.6 \mathrm{~m}-7.1 \mathrm{~m}$, and the elevation of existing wharves is about $7.1 \mathrm{~m}-7.6 \mathrm{~m}$. The surrounding environment of the foundation pit is shown in Figure 3.

\section{Engineering Geology}

3.1. Engineering Geological Conditions. According to the survey report, within the control of the depth of exploration holes, the site rock and soil layers are divided into the Quaternary filling $\left(Q^{\mathrm{ml}}\right)$, alluvial soil $\left(Q^{\mathrm{al}}\right)$, residual soil $\left(Q^{\mathrm{el}}\right)$, and Yanshanian bedrock $\left(r_{5}^{3}\right)$ according to the geological origin. Geological profile around the foundation pit is shown in Figure 4. Geotechnical engineering parameters of the soil layer within the excavation range of the foundation pit are shown in Table 1.

At the excavation depth of the foundation pit, the soil at the site is sandy plain fill, silt, medium sand, sandy cohesive soil, and fully weathered rock. The bottom of the foundation pit is basically located in the silt layer and partly in the medium sand layer.

\subsection{Special Geological Conditions in Nansha, Guangzhou,} Guangdong Province, China. Nansha District, Guangzhou City, Guangdong Province, China (Figure 5) is located at the junction of the Pearl River Estuary and Lingding Ocean. It is the frontier of the Pearl River Delta alluvial plain. The surface is mainly Quaternary sediment; deep sea-land mud is deposited in the rock and soil layers. Hence, soft soil in the whole area is distributed in large areas and thick layers, and the local distribution is intermittent. The genetic types of soft soil are mainly coastal and delta deposits. The clay in the Nansha area of Guangzhou City is coastal soft clay deposited in recent years. It is gray-colored, saturated, fluid-plastic, well-developed micro-bedding as well as with shell 


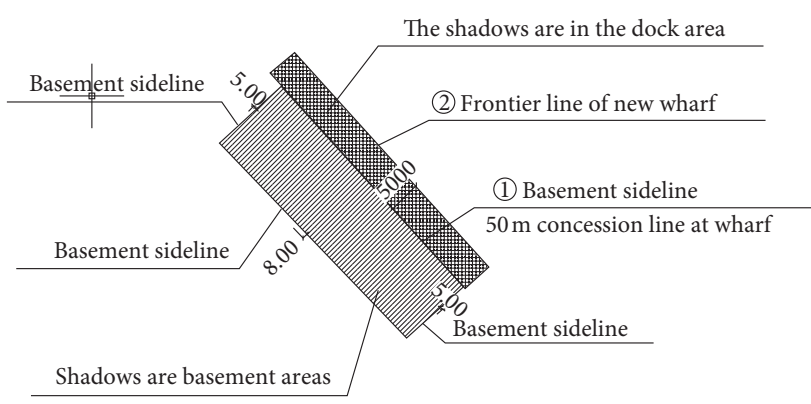

(a)

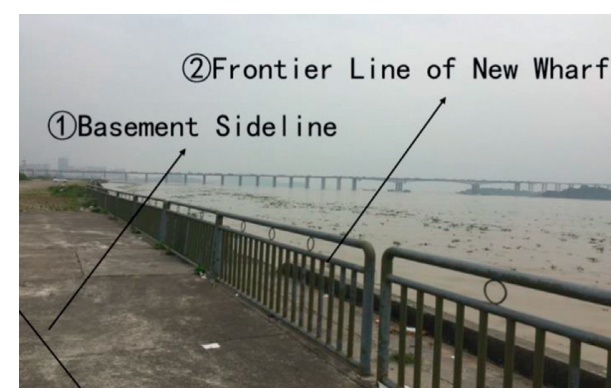

(b)

FIGURE 2: Renovation plan of the wharf. (a) Layout plan. (b) Corresponding location on-site.

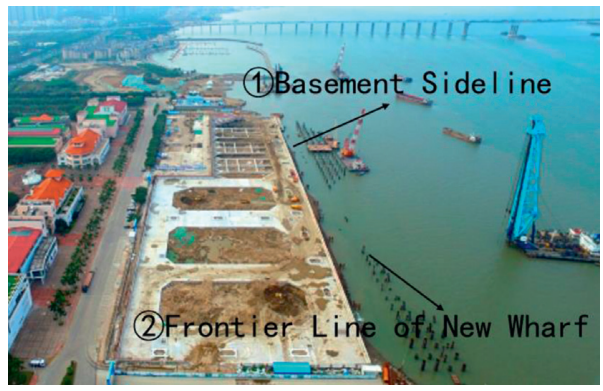

FIGURE 3: Environmental map of the foundation pit surroundings.

fragments and humus. It is mainly composed of silt, silty clay, or silty clay sandwiched between thin silt and fine sand along the bedding surface. The homogeneity of soil is poor, whereas it disperses in the form of pancakes after drying.

Due to the alternating hydraulic action of rivers and waves, the soft soil in the Nansha area is deposited alternately by silt and thin sand with horizontal bedding. In the surface and subsurface layers, most of the areas are singlelayer deep silt or silty soil with the underlying sand layer. Depending on the distribution of rivers, topographic effects, and geological formation conditions, the thickness of silt varies from place to place, but generally in the range of $20 \mathrm{~m}-30 \mathrm{~m}$, while in the land area formed by dredger fills, the thickness can even reach $40 \mathrm{~m}$. Complex cross-fertilization of rivers and tides results in staggered deposition of silt and thin sand layers, forming irregular pinch-out layers or lens interlayers.

3.3. State of the Pearl River Estuary. Pearl River Estuary is an important area in Guangdong Province with frequent disasters. This project is located in one of the Pearl River estuaries.

3.3.1. Waves. The waves in the South China Sea are mainly caused by tropical cyclones and monsoons. During the monsoon period, the wind waves of the South China Sea appear in the monsoon direction. Many islands in the Pearl River Estuary and the offshore waves are transmitted to the Estuary by the barrier effect of these islands, along with refraction and diffraction. At the same time, the wave height

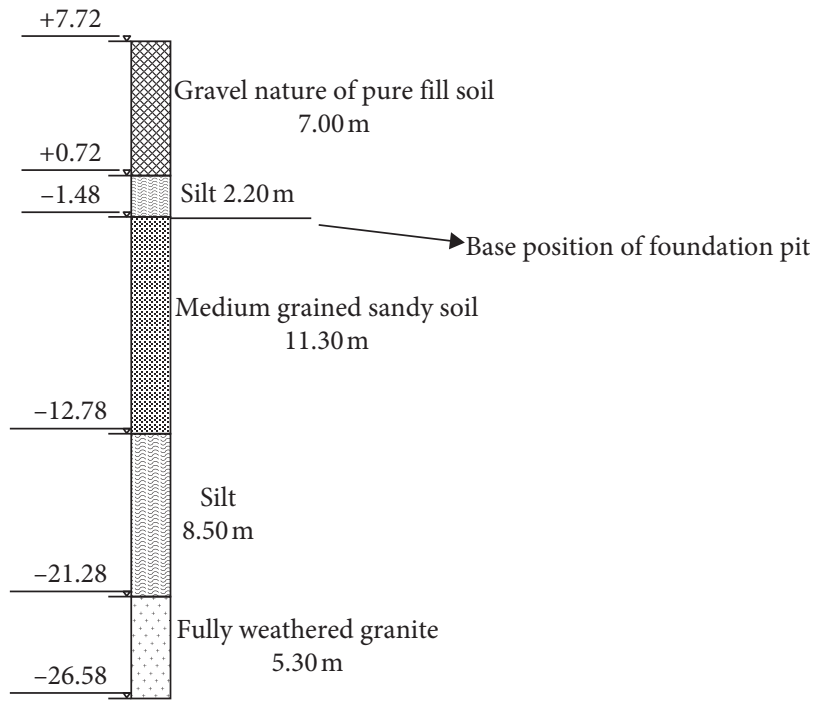

Figure 4: Geological profile around the foundation pit.

and direction often change greatly under the influence of shallow water depth and other factors. Figure 6 shows the distribution of the ultimate wave height during the foundation pit construction of this project.

3.3.2. Tides. Influenced by ocean climate and tropical cyclones, the tides in the Pearl River Estuary are mainly formed by the influence of topography, runoff, and meteorological conditions of the Pearl River Estuary after the tidal waves from the Pacific Ocean pass through the Luzon Strait into the South China Sea. They belong to the irregular semi-diurnal tide type. Its variation characteristics are as follows: there are two high tides on a cloudy day. However, the heights of two adjacent high tides or low tides are not equal; that is, the difference between two adjacent tides as well as the time of rising tide and ebb tide is not equal, which is consistent with the phenomenon of diurnal tides. The ebb tide in the Pearl River Estuary is aggravated by the influence of runoff discharge, while the ebb tide is restrained by runoff discharge. The ebb tide lasts longer than the rising tide, and the ebb tide speed is faster than the rising tide speed. The distribution of the 
TABLE 1: Geotechnical engineering parameters of soil layer within the excavation range of the foundation pit.

\begin{tabular}{|c|c|c|c|c|c|}
\hline Soil name & $\gamma /\left(\mathrm{kN} / \mathrm{m}^{3}\right)$ & $E_{\mathrm{s}} /(\mathrm{MPa})$ & $C /(\mathrm{kPa})$ & $\Phi /\left(^{\circ}\right)$ & Soil layer thickness $(\mathrm{m})$ \\
\hline Gravel nature of pure fill soil & 20.0 & 5.0 & 0.0 & 24.0 & $2.5 \sim 14.3$ \\
\hline Silt-(1) & 16.5 & 2.0 & 4.0 & 3.0 & $0.5 \sim 7.4$ \\
\hline Medium grained sandy soil-(1) & 20.0 & 6.0 & 0.0 & 27.0 & $2.0 \sim 13.1$ \\
\hline Silt-(2) & 16.5 & 2.0 & 4.0 & 3.0 & $1.7 \sim 24.5$ \\
\hline Fully weathered granite & 19.0 & 12.0 & 22.0 & 18.0 & $1.5 \sim 11.5$ \\
\hline
\end{tabular}

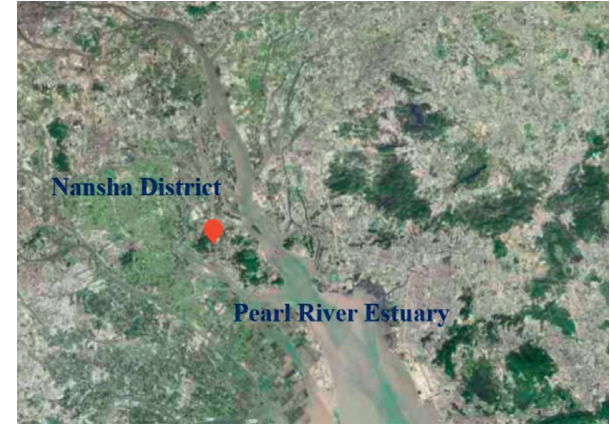

Figure 5: Location relationship between Nansha and Pearl River Estuary.

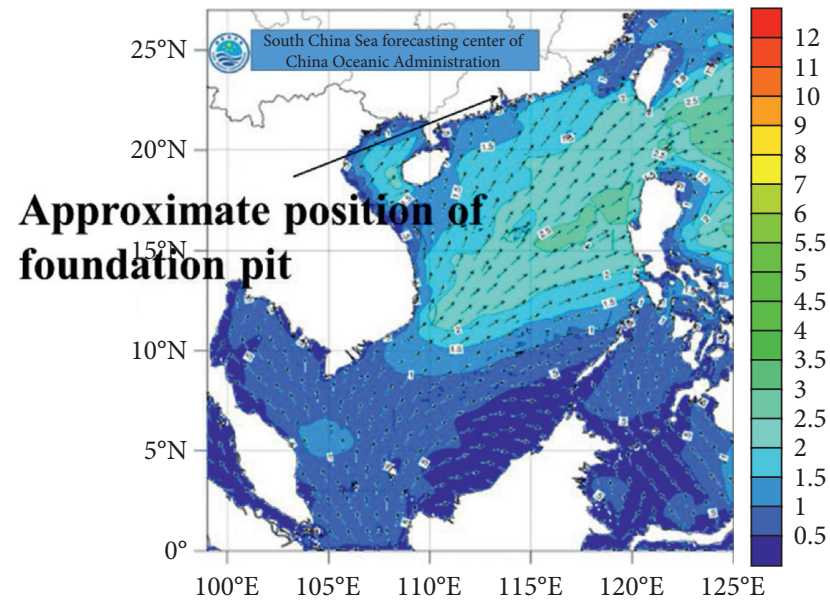

Figure 6: Wave height map of the South China Sea (unit: m).

tidal water level during the foundation pit construction is shown in Figure 7.

3.3.3. Typhoons. Guangdong Province is located in the tropical and subtropical monsoon climate zone, with the South China Sea in the south and the West Pacific in the east. It is the province with the longest coastline and is also one of the main areas where typhoons land in China. Strong typhoons landing in Guangdong have brought storm surges to the Pearl River Estuary.

During the construction period, the landing of the $22^{\text {nd }}$ typhoon in 2018, "Mangosteen," had a serious impact on the project. It is a severe typhoon affecting most areas of the Pearl River Delta since Typhoon Hope No. 8 in 1979. The

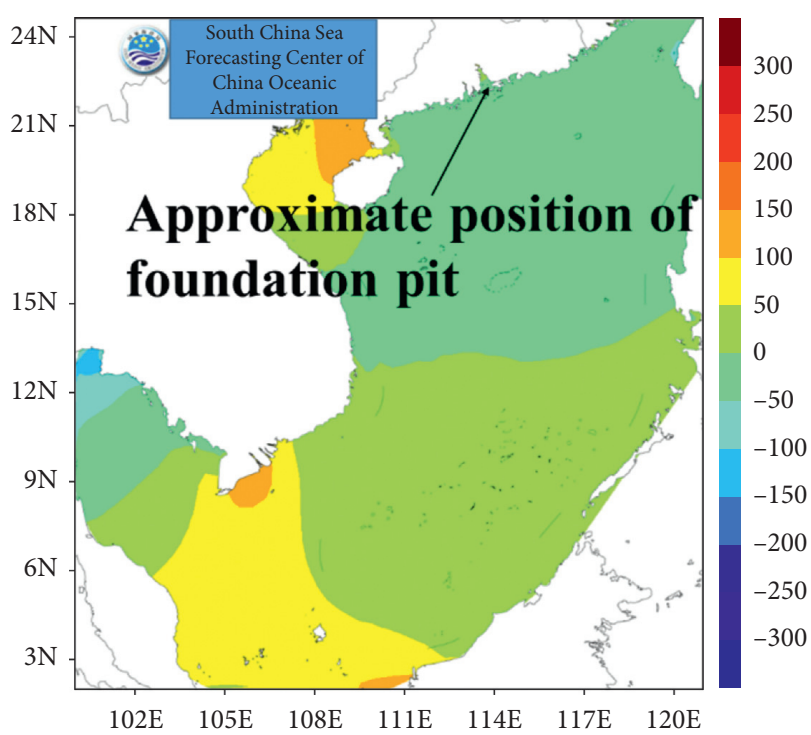

Figure 7: Tidal water level map of the South China Sea (unit: $\mathrm{cm}$ ).

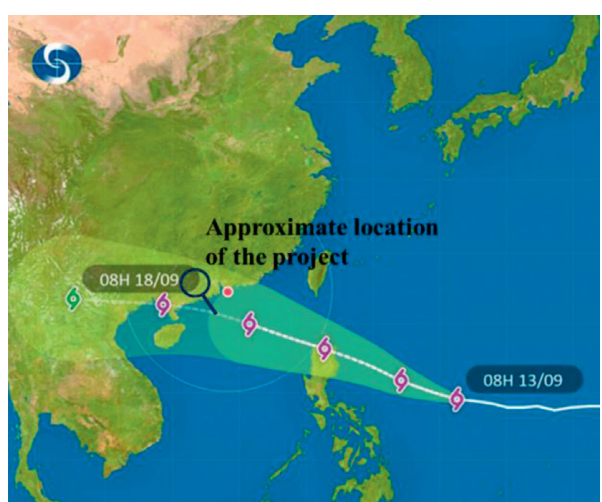

Figure 8: Typhoon "Mangosteen" path and meteorological map.

characteristics of typhoon "Mangosteen" include (a) strong wind intensity, with the maximum wind force near the center of over 17 levels (65 meters/second); (b) wind intensity lasting 66 hours; and (c) strong and broad wind range and cloud system. The direct range of the cloud system is 100 kilometers, whereby the influence of wind and rain is tremendous. Thus, the coastal wind force in the central and western parts of South China would be 14-16 levels, and gusts would last 17 hours. Above Grade 1, there are heavy rainstorms in southern Guangdong and other areas. The central route of the typhoon is shown in Figure 8. 

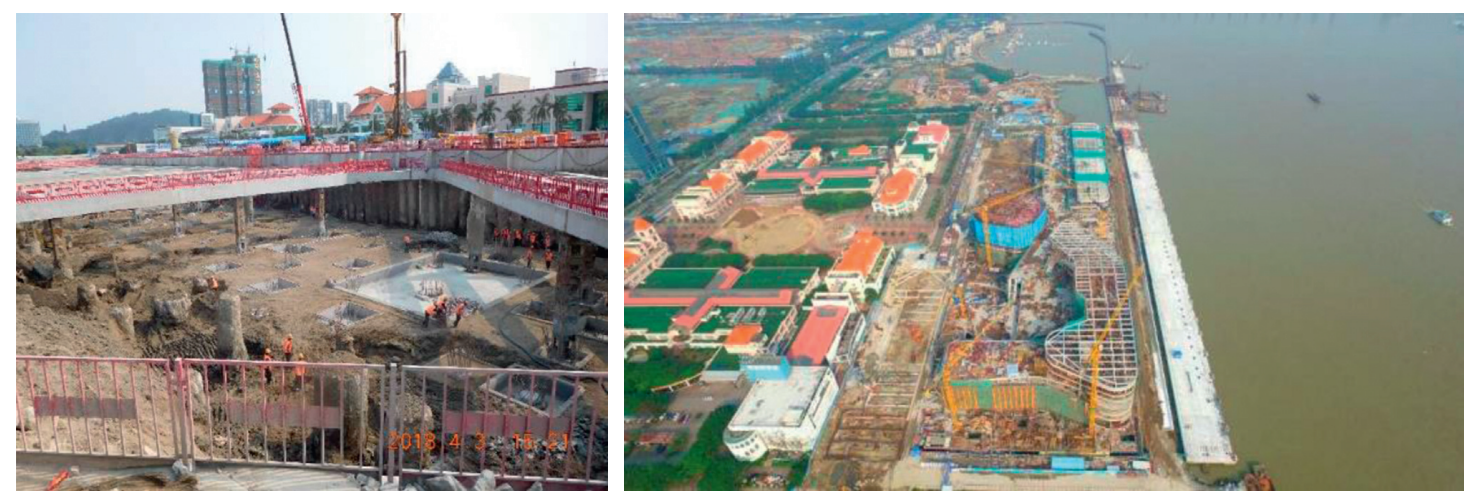

FIGURE 9: Environmental map of the foundation pit surroundings.

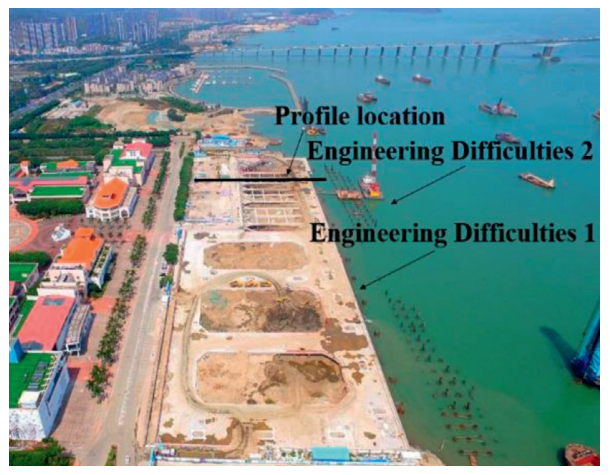

(a)

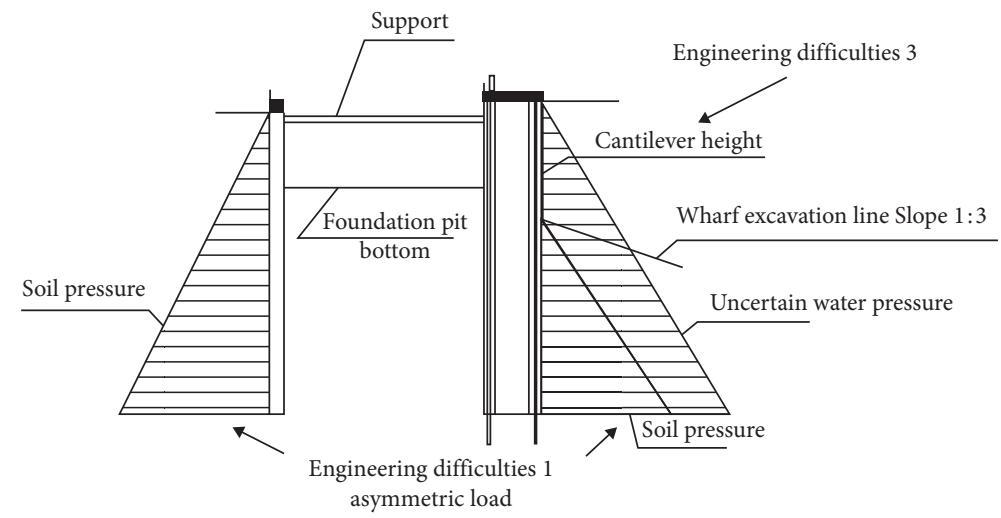

(b)

Figure 10: Plane and section location map of engineering difficulties.
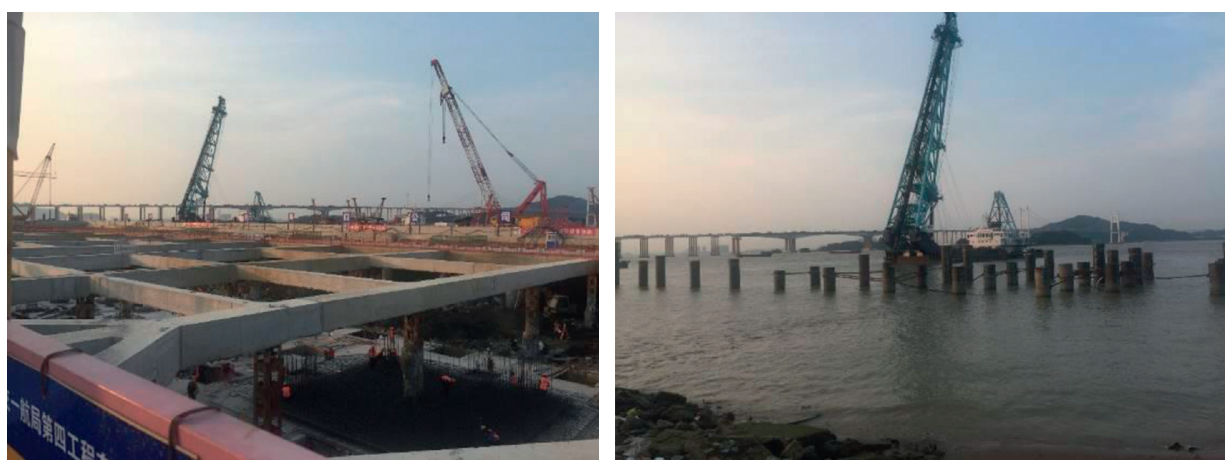

FIGURE 11: Construction site map of the wharf.

\section{Key Technologies}

4.1. Engineering Difficulties. Based on the surrounding environment shown in Figure 9, geological engineering conditions, special geological conditions in Nansha, and sea conditions in the Pearl River Estuary, and combined with the actual situation of the project, the existing engineering difficulties in the foundation pit project are as follows. Furthermore, the existing engineering difficulties correspond to the marked position in Figure 10:
(1) Waves propagate to the harbor, that is, the location of the project. Wave loads of different nature are generated according to the depth of water, resulting in different wave loads at different locations of the foundation pit. Tidal effects cause constant changes in the water level. As a part of the load, the dynamic changes of water level would inevitably lead to changes in the load size, as well as changes in the nature of wave loads. The extreme weather event (typhoon "Mangosteen") occurred in Guangdong 


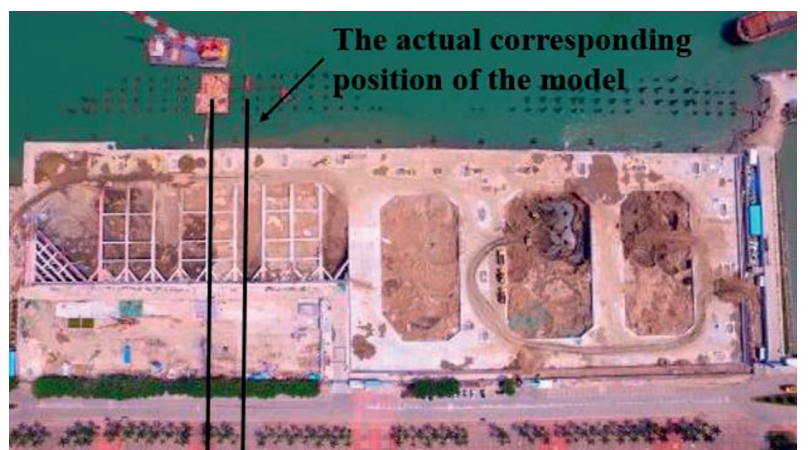

Figure 12: Plane diagram of model for impact analysis of wave load on the foundation pit.

during the construction of the foundation pit and aggravated these two effects. The changes caused by the superposition of waves, tides, typhoons, and other factors led to the asymmetric load acting on both sides of the foundation pit supporting structure, seriously affecting its reliability. Therefore, the foundation pit of this project needs to be designed with full consideration of wave force and adverse conditions of tidal and extreme weather typhoon effects.

(2) The foundation pit site is adjacent to the wharf construction site (Figure 11), whereby the wharf construction would have a significant impact on the foundation pit. Among them, the hammering of steel pipe piles in wharf construction and vibration loads caused by this vibration and sand washing in wharf backfilling are the two most important considerations. Unlike the conventional offshore foundation pit, there are still some vibration loads that cannot be determined. Therefore, the design of the supporting structure of the foundation pit should fully consider the safety of the foundation pit.

(3) There are two different situations in earthwork excavation of wharf and foundation pit. Earthwork excavation is conducted first in the wharf and foundation pit. When the wharf is excavated first and dug to the bottom, the supporting structure of the foundation pit has a considerable cantilever height. The Earth pressure on the side of the foundation pit near the sea is changed due to the excavation of the soil. The load on both sides of the foundation pit is unbalanced. Thus, this may cause the supporting structure to fail, resulting in a serious accident. Given this situation, therefore, it is necessary to fully consider the various load situations of wharf and foundation pit construction in the design. Three working conditions are considered: (a) excavation of foundation pit when the wharf is excavated before backfilling, (b) excavation of foundation pit after backfilling of wharf excavation, and (c) excavation of foundation pit after the excavation of wharf.

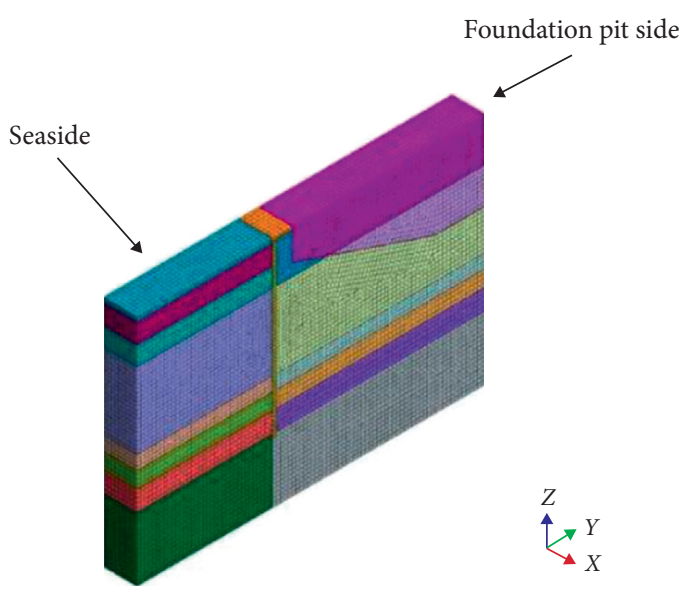

FIGURE 13: Profile of model for impact analysis of wave loads on the foundation pit.

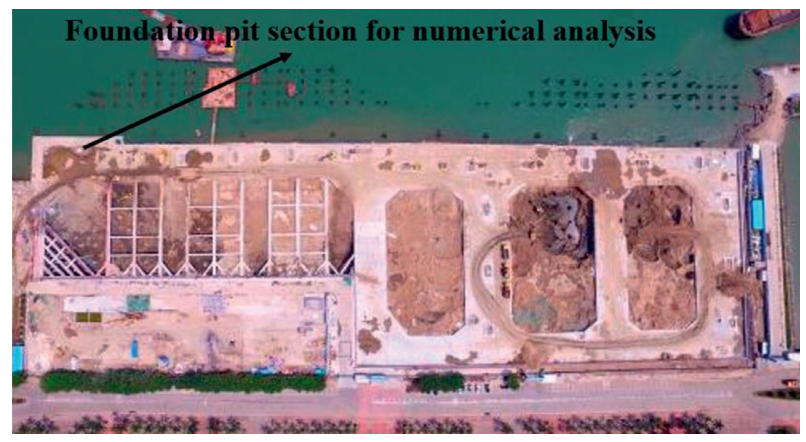

Figure 14: Analytical section plane position map.

\subsection{Relevant Theory and Analysis of the Effect of Waves and Tides on Supporting Structures}

4.2.1. Relevant Theory. The influence of waves and tides on supporting structures is an important problem in coastal engineering, where these two factors are the main external loads. In the analysis of the arrival load of wave tides, the theory of calculating the standing wave force under the action of wave crest is as follows:

(1) Calculation of wave surface elevation

$$
\frac{\eta_{c}}{d}=B_{\eta}(H / d)^{m}
$$

where $\eta_{c}$ is the wavefront elevation (m); $d$ is the water depth in front of buildings (m); $B_{\eta}$ is the coefficient; $H$ is the wave height of wave propagating at the location of buildings ( $\mathrm{m})$; and $m$ is the coefficient.

$$
B_{\eta}=2.3104-2.5907 T_{*}^{-0.5941},
$$

where $T_{*}$ is dimensionless. 

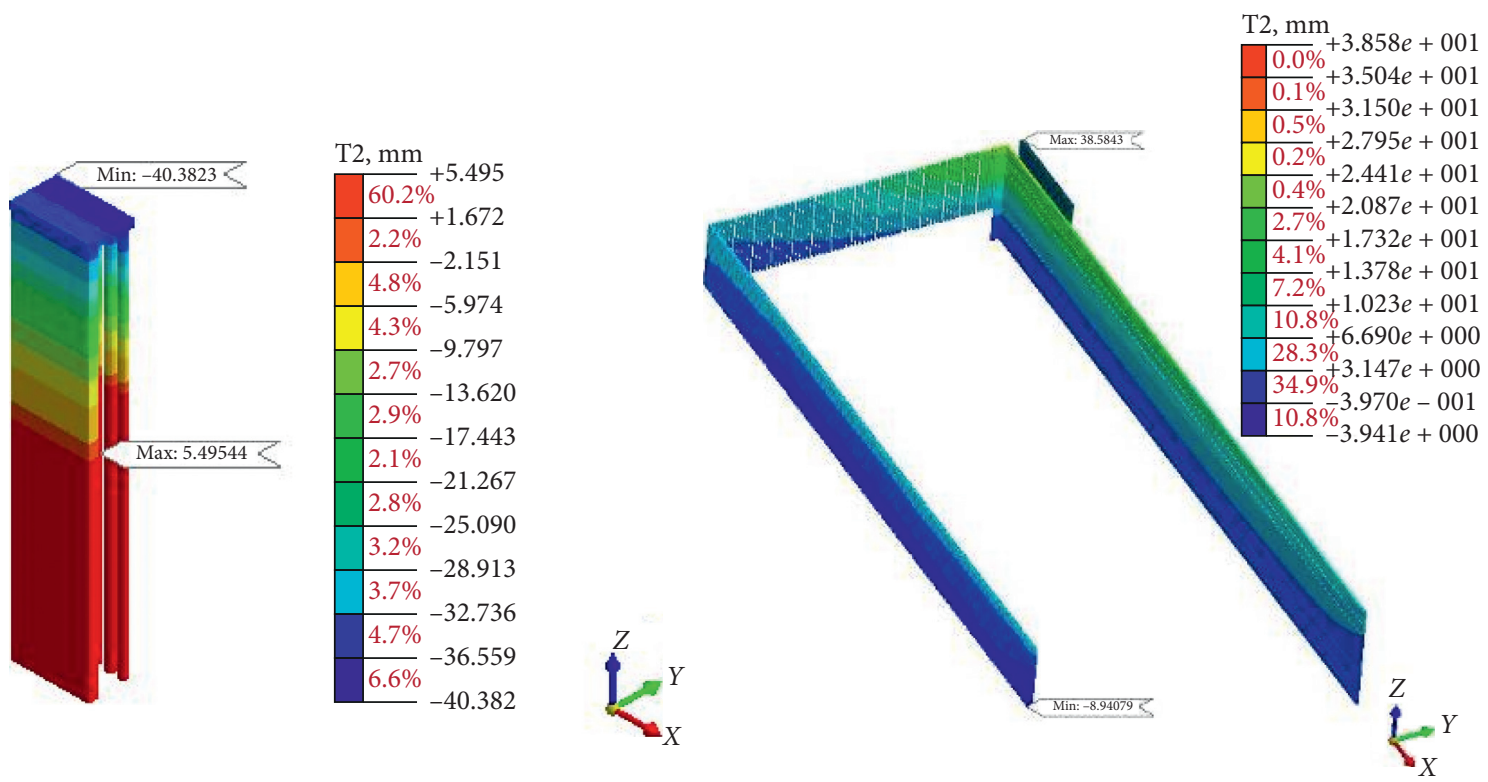

FIGURE 15: Displacement of supporting structure $(\mathrm{mm})$ after the excavation of the foundation pit without backfilling of the wharf.
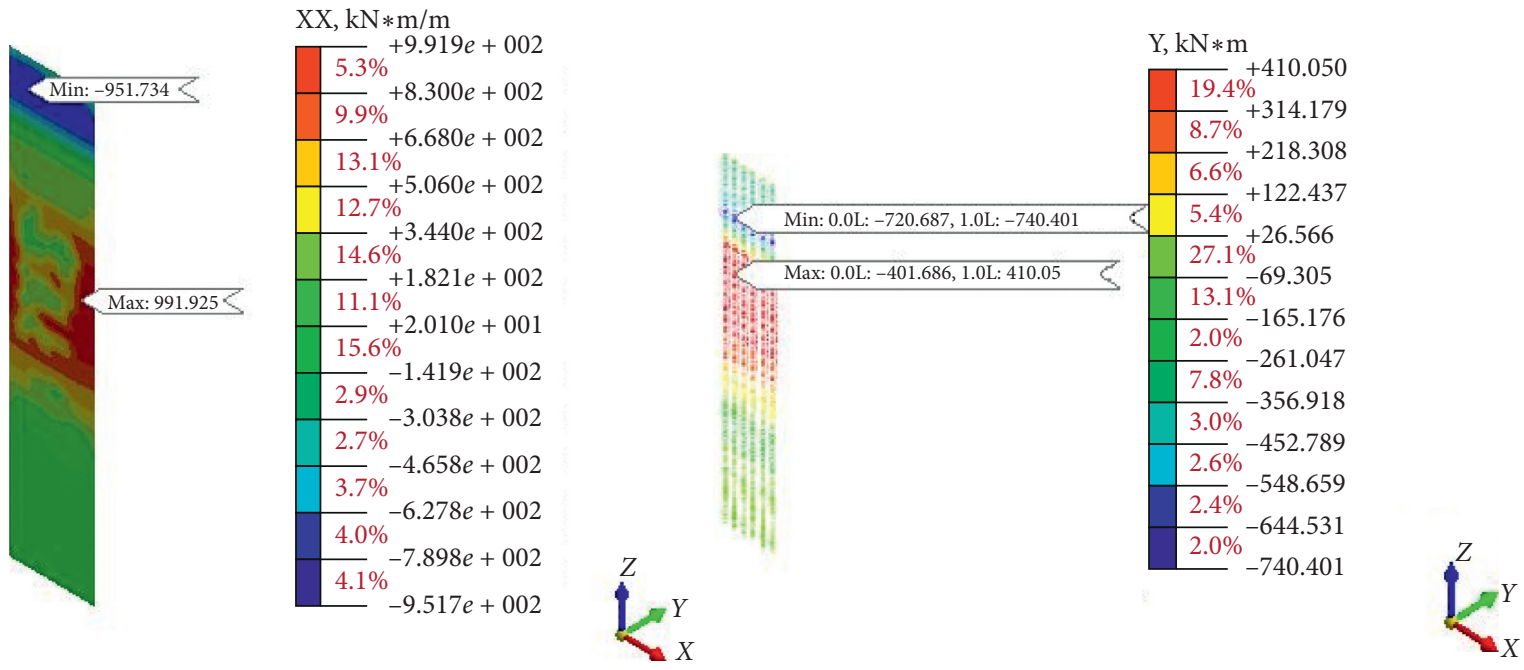

FiguRE 16: No backfilling of wharf, after excavation of foundation pit to the end, the bending moment per meter of supporting structure (unit: $\mathrm{kN} \cdot \mathrm{m}$ ).

$$
\begin{aligned}
m & =\frac{T_{*}}{\left(0.00913 T_{*}^{2}+0.636 T_{*}+1.2515\right)}, \\
T_{*} & =\bar{T} \sqrt{\frac{g}{d}},
\end{aligned}
$$

where $\bar{T}$ is the average period (s) and $g$ is the gravity acceleration $\left(\mathrm{m} / \mathrm{s}^{2}\right)$.

(2) Calculating the wall wave pressure intensity above the still water surface

$$
\frac{h_{c}}{d}=\frac{2 \eta_{c} / d}{n+2}
$$

where $h_{c}$ is the location of the action point of wave pressure strength $P_{a c}$ above the static water surface; $P_{a c}$ is the wall wave pressure strength corresponding to $h_{c}(\mathrm{kPa})$; and $n$ is the exponent of the distribution curve of wave pressure intensity above the still water surface, the value of which is the maximum of two numbers in the formula. 

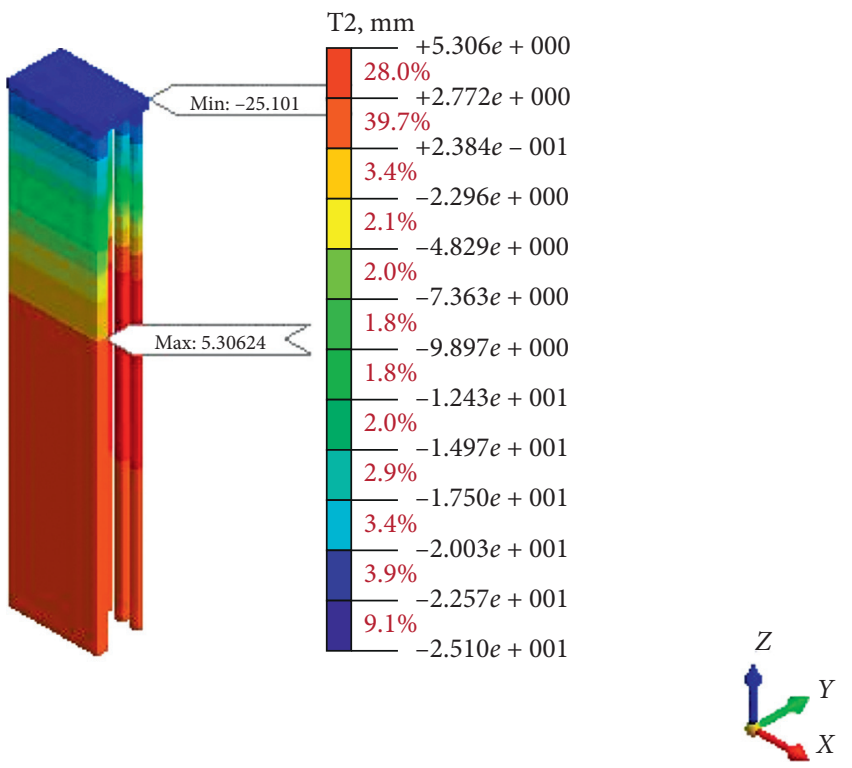

FIGURE 17: Horizontal displacement of supporting structure after the foundation pit excavation after wharf backfilling (unit: mm).

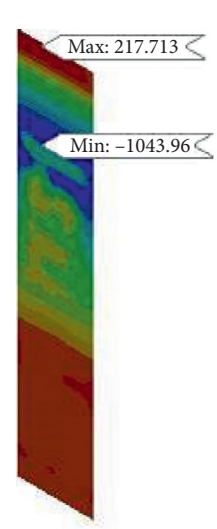

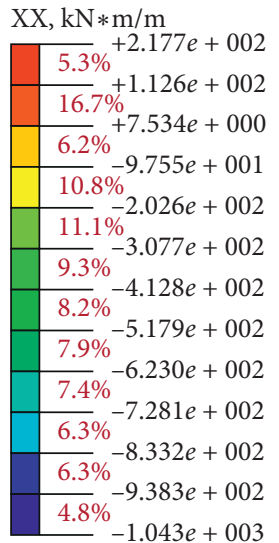
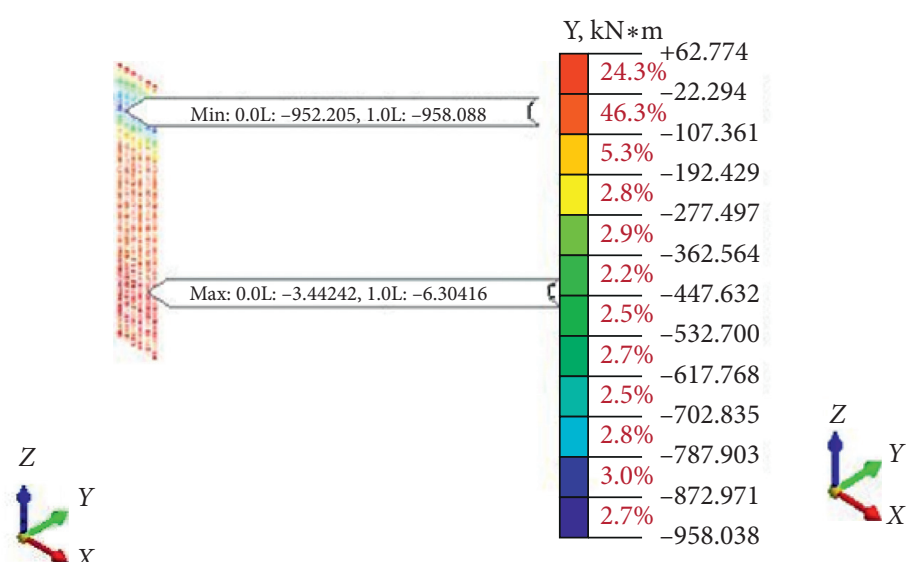

FIGURE 18: After backfilling of wharf, the bending moment per meter of the foundation pit excavation to the end of supporting structure (unit: $\mathrm{kN} \cdot \mathrm{m}$ ).
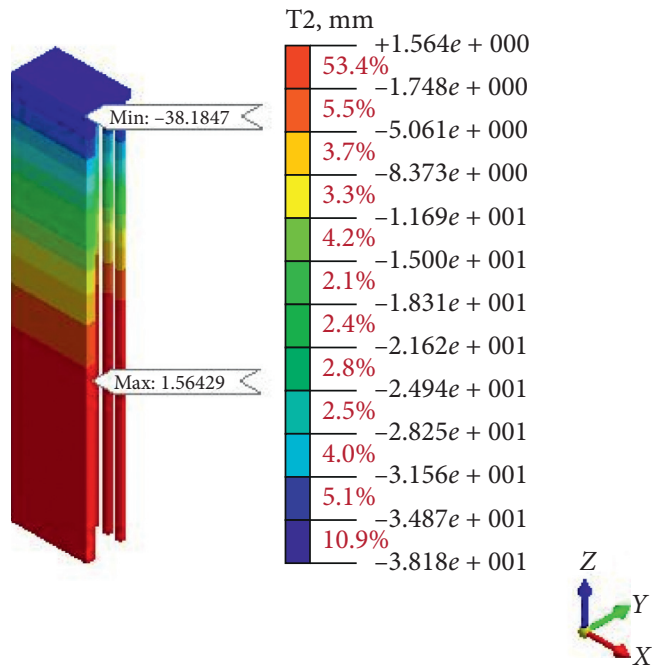

FIGURE 19: Horizontal displacement of the supporting structure after wharf excavation (unit: $\mathrm{mm}$ ). 

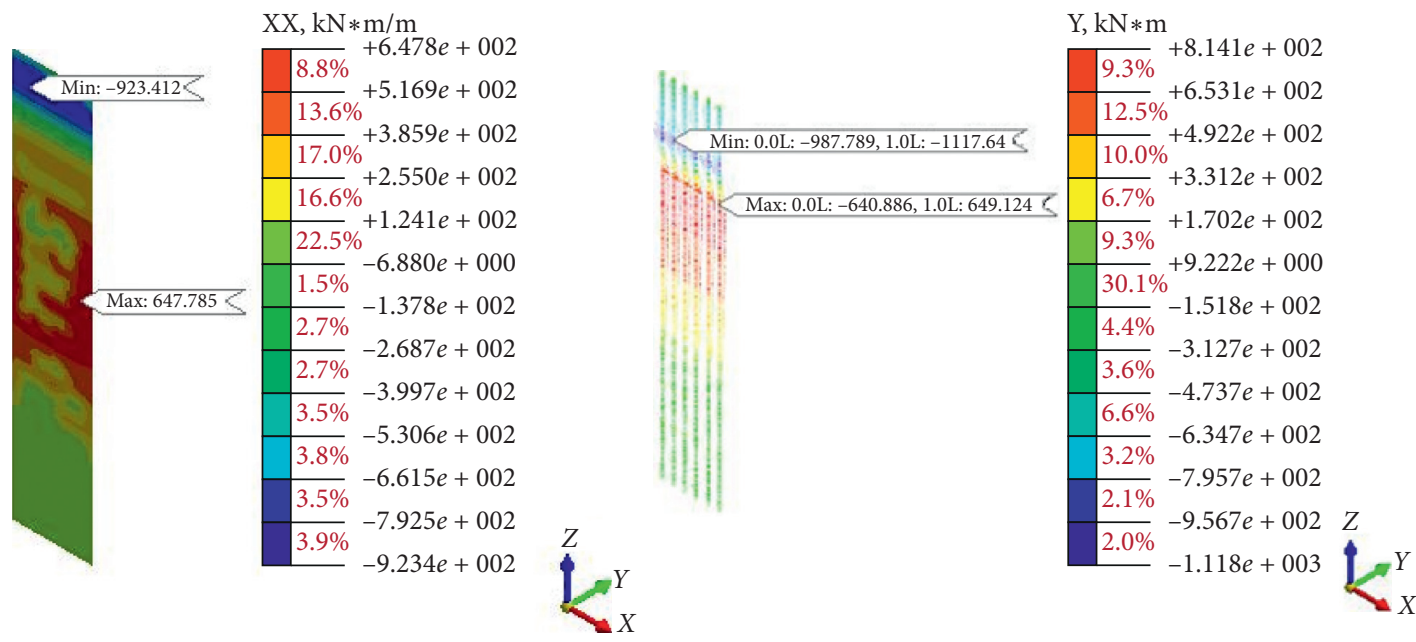

Figure 20: Bending moment per meter of the supporting structure after excavation of wharf (unit: $\mathrm{kN} \cdot \mathrm{m}$ ).

$$
\frac{P_{a c}}{\gamma d}=\frac{P_{o c}}{\gamma d} \frac{2}{(n+1)(n+2)},
$$

where $P_{o c}$ is the wave pressure intensity on the hydrostatic surface $(\mathrm{kPa})$ and $\gamma$ is the water severity $\left(\mathrm{kN} / \mathrm{m}^{3}\right)$.

$$
n=\max \left[0.636618+4.23264(H / d)^{1.67}, 1.0\right]
$$

(3) Calculation of wave pressure strength at $P_{o c}$ and other characteristic points on the wall

$$
\frac{P}{\gamma d}=A_{p}+B_{p}\left(\frac{H}{d}\right)^{q}
$$

where $A_{p}, B_{p}$, and $q$ are empirical coefficients.

(4) Calculation of total horizontal wave forces on a wall of unit length

$$
\frac{P_{c}}{\gamma d^{2}}=\frac{1}{4}\left[2 \frac{P_{o c}}{\gamma d} \frac{\eta_{c}}{d}+\frac{P_{o c}}{\gamma d}\left(1+\frac{2 h_{c}}{d}\right)+\frac{2 P_{b c}}{\gamma d}+\frac{P_{d c}}{\gamma d}\right],
$$

where $P_{b c}$ is the wall wave pressure strength corresponding to $\mathrm{d} / 2(\mathrm{kPa}) ; P_{c}$ is the horizontal total wave force on a wall of unit length $(\mathrm{kN} / \mathrm{m})$; and $P_{d c}$ is the wave pressure strength at wall bottom $(\mathrm{kPa})$.

(5) Calculation of total horizontal wave moments on a wall of unit length

$$
\begin{aligned}
\frac{M_{c}}{\gamma d^{3}}= & \frac{1}{2} \frac{P_{a c}}{\gamma d} \frac{\eta_{c}}{d}\left[1+\frac{1}{3}\left(\frac{\eta_{c}}{d}+\frac{h_{c}}{d}\right)\right]+\frac{1}{24} \frac{P_{o c}}{\gamma d}\left[5+\frac{12 h_{c}}{d}+4\left(\frac{h_{c}}{d}\right)^{2}\right] \\
& +\frac{1}{4} \frac{P_{b c}}{\gamma d}+\frac{1}{24} \frac{P_{d c}}{\gamma d}
\end{aligned}
$$

where $M_{c}$ is the horizontal total wave torque on a wall of unit length $(\mathrm{kN} \cdot \mathrm{m} / \mathrm{m})$.

(6) Calculation of wave buoyancy force on the bottom of a unit length wall

$$
P_{u c}=\frac{P_{d c} B}{2},
$$

where $P_{u c}$ is the wave buoyancy force on the bottom of unit length wall $(\mathrm{kN} / \mathrm{m})$ and $B$ is the bottom width of the straight wall $(\mathrm{m})$.

4.2.2. Practical Analysis of the Effect of Waves and Tides on Supporting Structures. The analysis of waves, tides, typhoons, wharf side construction, and other factors in engineering difficulties 1,2 , and 3 is combined with the longterm observation data of sea waves in the site area and considers various unfavorable conditions the average wave height of extremely high water level is $1.6 \mathrm{~m}$. Combined with waves and tidal forces for vertical wall buildings, the function theory and the large-scale finite element analysis software Midas GTS are used for design and calculation; specific analysis ideas are as follows:

(1) The criteria for determining the wave patterns (standing wave, far breaking wave, and near breaking wave) of dark, medium, and low beds are obtained by calculation.

(2) According to the calculation theory of waves and tidal forces, the wave and tidal loads under the action of wave crests and valleys in different wave states $P_{c}$, $M_{c}$, and $P_{u c}$ are calculated.

(3) Combining the wave and tidal loads calculated by theory, the analysis model is established by using Midas GTS (as shown in Figures 12 and 13). The action force is applied to the model and the sinusoidal wave loads are analyzed by the time history.

(4) According to the corresponding problems in difficulty 3 of the project, three working conditions of the 


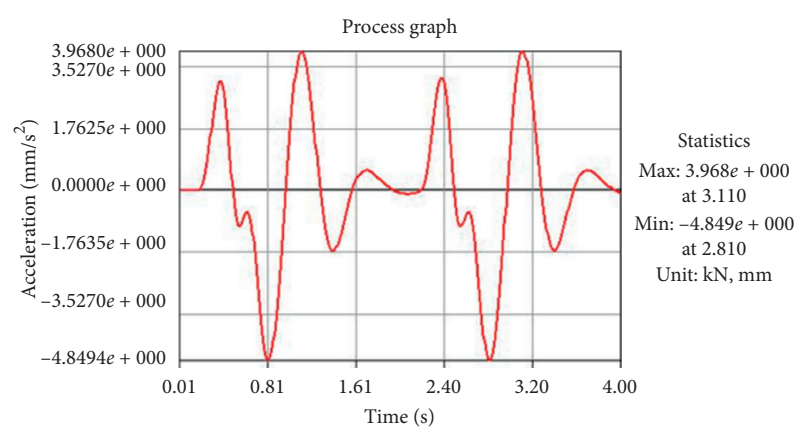

FIgURE 21: Acceleration at the top of the foundation pit cover near the wharf.

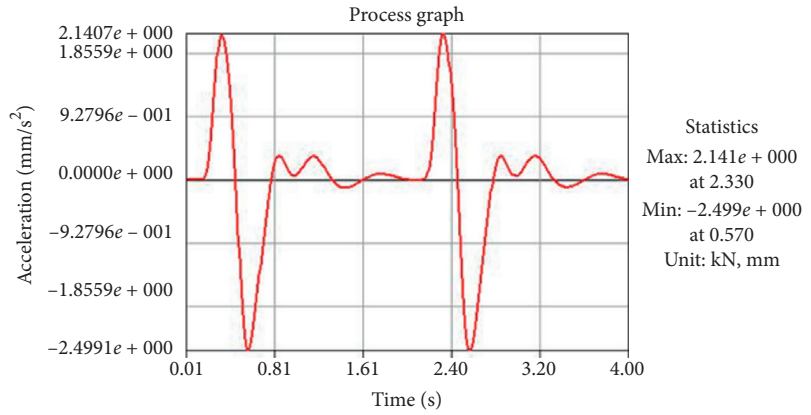

Figure 22: Ground acceleration at the pit bottom.

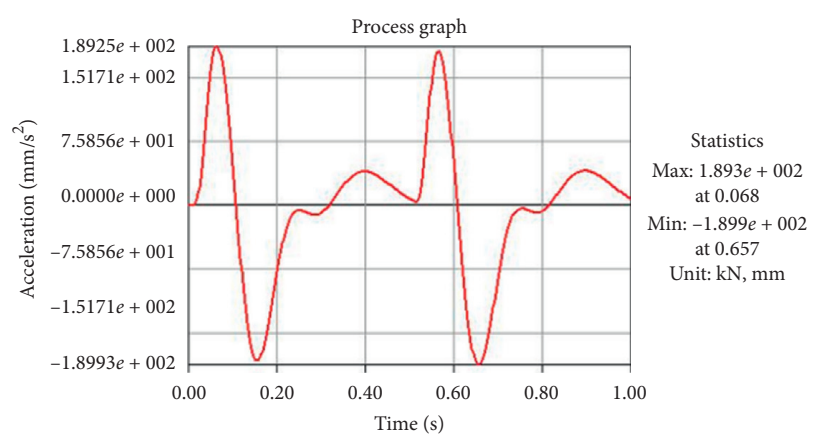

Figure 23: Acceleration at the top of the foundation pit cover near the wharf.

wharf identified earlier are simulated and analyzed, respectively; the displacements and the bending moment per meter of the foundation pit supporting structure are obtained.

(1) Analysis Results of the First Excavation of the Wharf under Wave Loads. The excavation of the wharf adjacent to the foundation pit site is performed first; the excavation of the foundation pit is simulated without the backfilling of the wharf. The displacement results of the retaining structure of the foundation pit after excavation (as shown in Figures 14 and 15) and the bending moment per meter of the retaining structure of the foundation pit (Figure 16) are obtained.

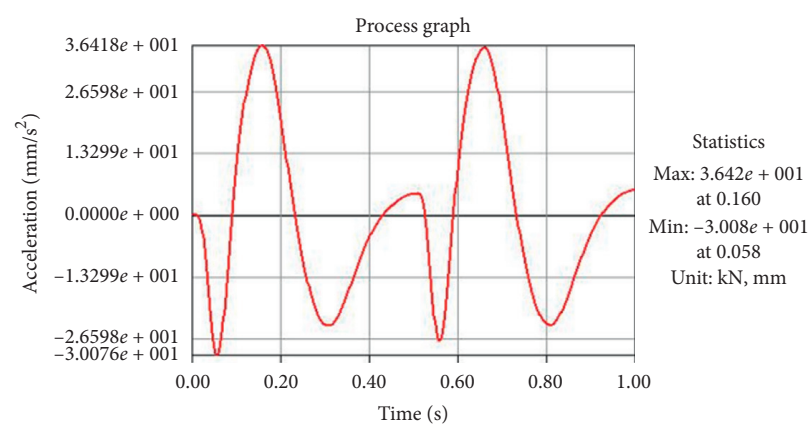

Figure 24: Ground acceleration at the pit bottom.

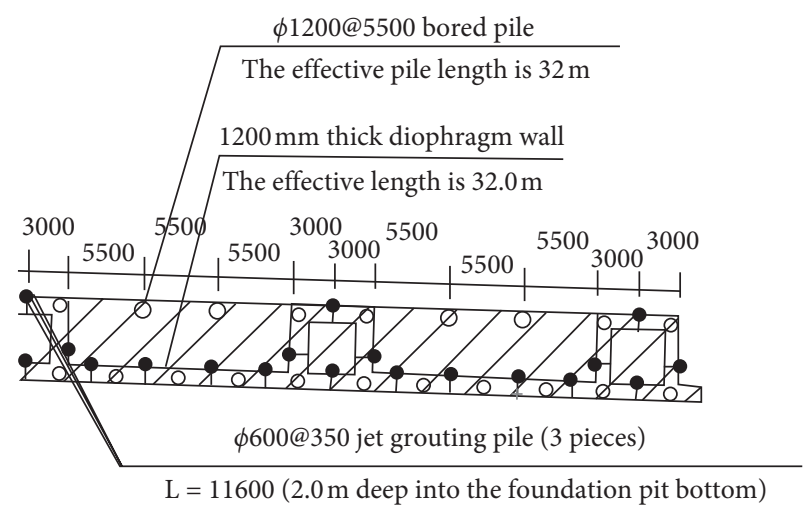

Figure 25: Section plan of the lattice diaphragm wall.

(2) Wharf Backfilling under the Action of Wave Loads. The excavation of the wharf adjacent to the foundation pit site is performed first, and the excavation of the foundation pit is simulated when the wharf backfilling is completed. The displacement of the supporting structure of the foundation pit after the foundation pit excavation is obtained (Figure 17) along with the bending moment of the supporting structure of the foundation pit per meter (Figure 18).

(3) Foundation Pit Excavated Firstly under the Action of Wave Loads. The working condition of excavation is simulated when the foundation pit is excavated first and after the adjacent wharf is excavated. The displacement results of the foundation pit supporting structure after the wharf is excavated are shown in Figure 19; the bending moment per meter of the foundation pit supporting structure (Figure 20) is obtained.

4.3. Relevant Theory and Analysis of the Influence of Wharf Construction on Supporting Structures. According to the introduction of engineering difficulty 2 , the foundation pit site is adjacent to the wharf construction site; therefore, the impact of the wharf construction on the foundation pit cannot be neglected. Hence, the impact of hammering, vibration, and sand washing loads of steel pipe piles in the wharf construction is analyzed. 


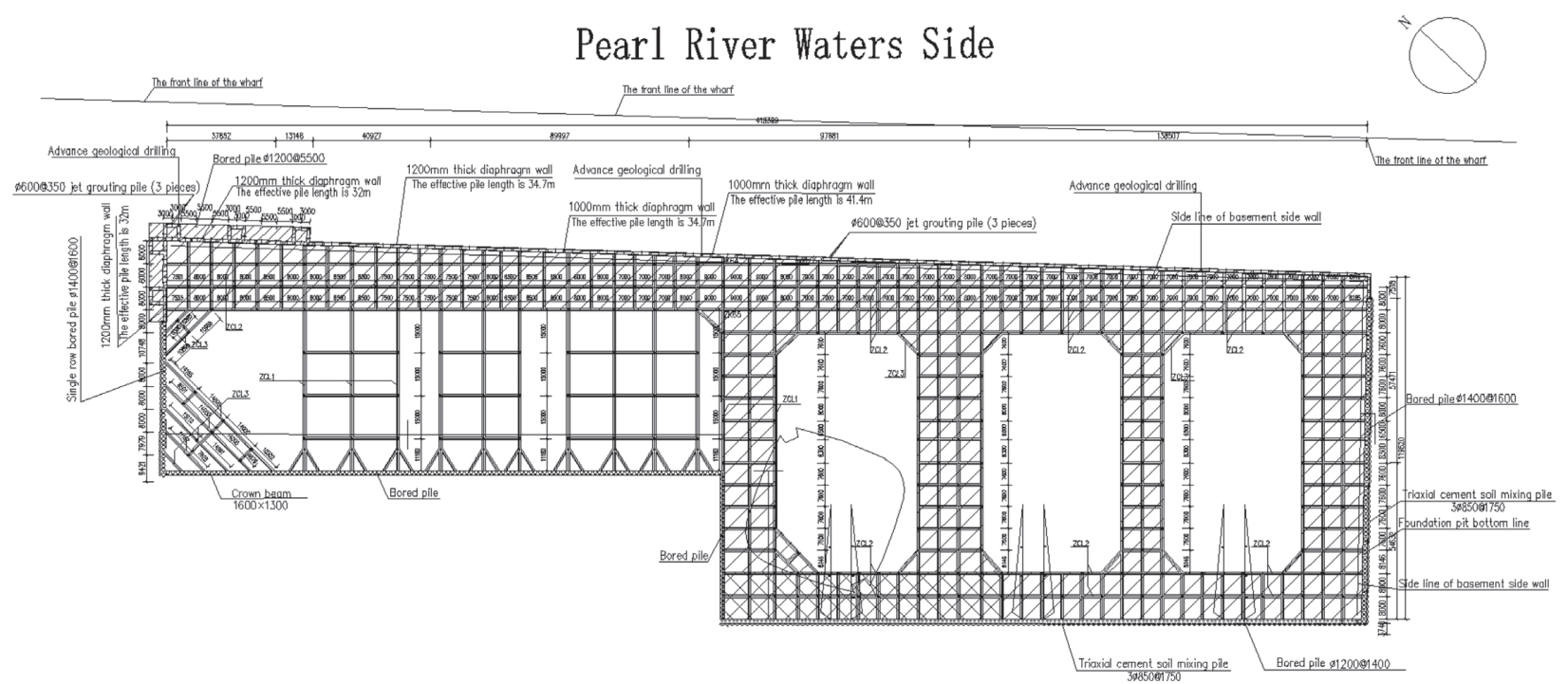

Figure 26: Plane layout of the foundation pit support.

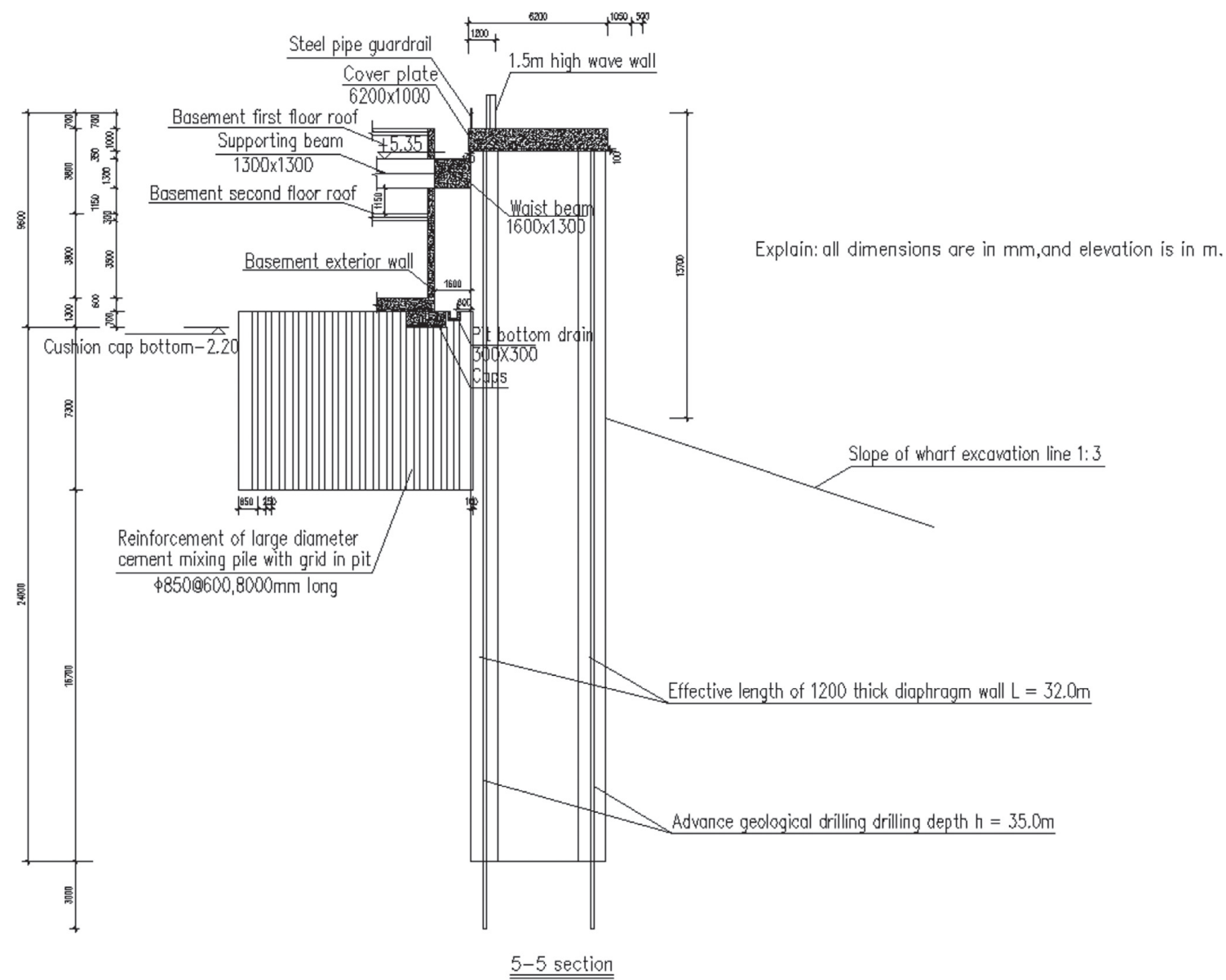

FIGURE 27: Section profile of the foundation pit.

4.3.1. Relevant Theory. In view of the vibration effects caused by the construction of steel pipe piles and vibroflushing sand around the engineering foundation pit, the hammering load is regarded as continuous impulsive loads. Each impulsive load would produce a dynamic response increment. By using the principle of superposition, all the response increments are time-dependent. The dynamic response of the structural system is 


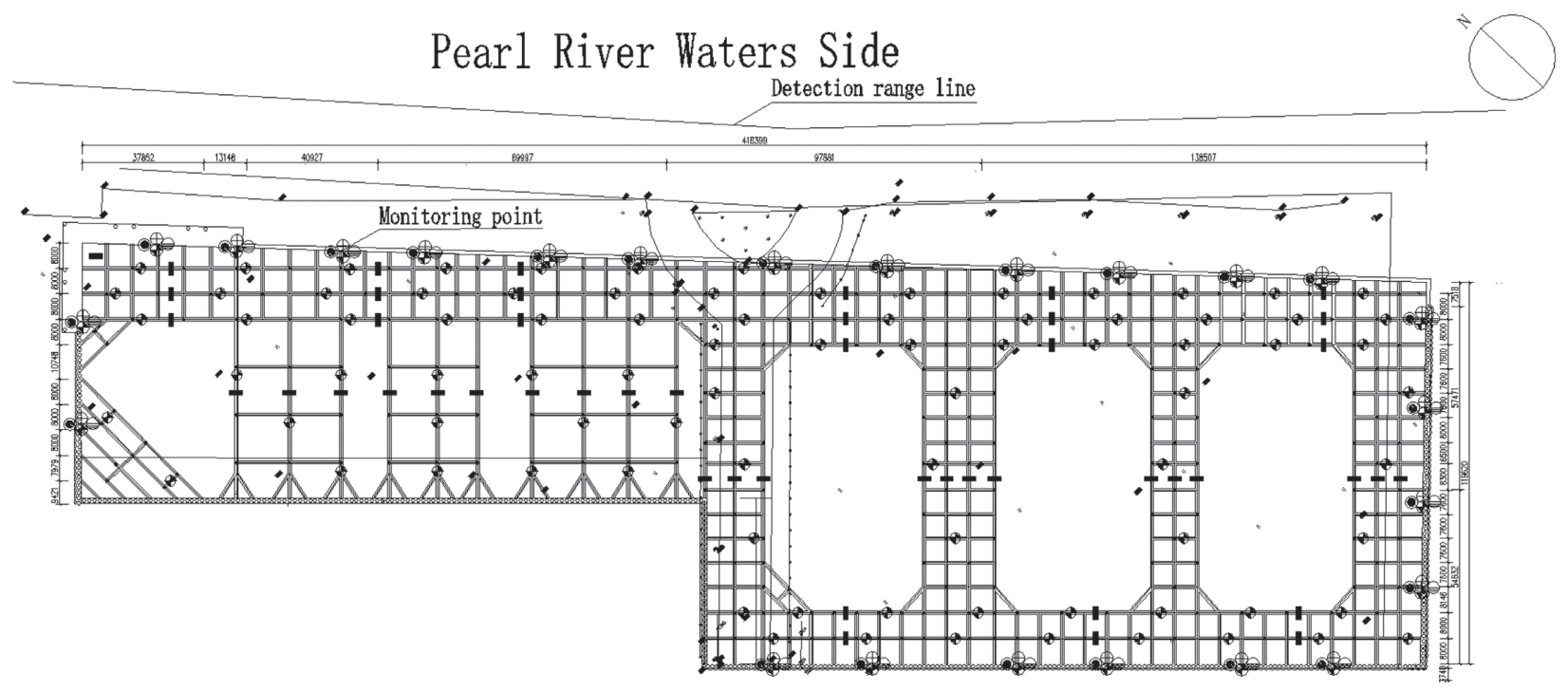

Figure 28: Plane layout of the foundation pit monitoring.

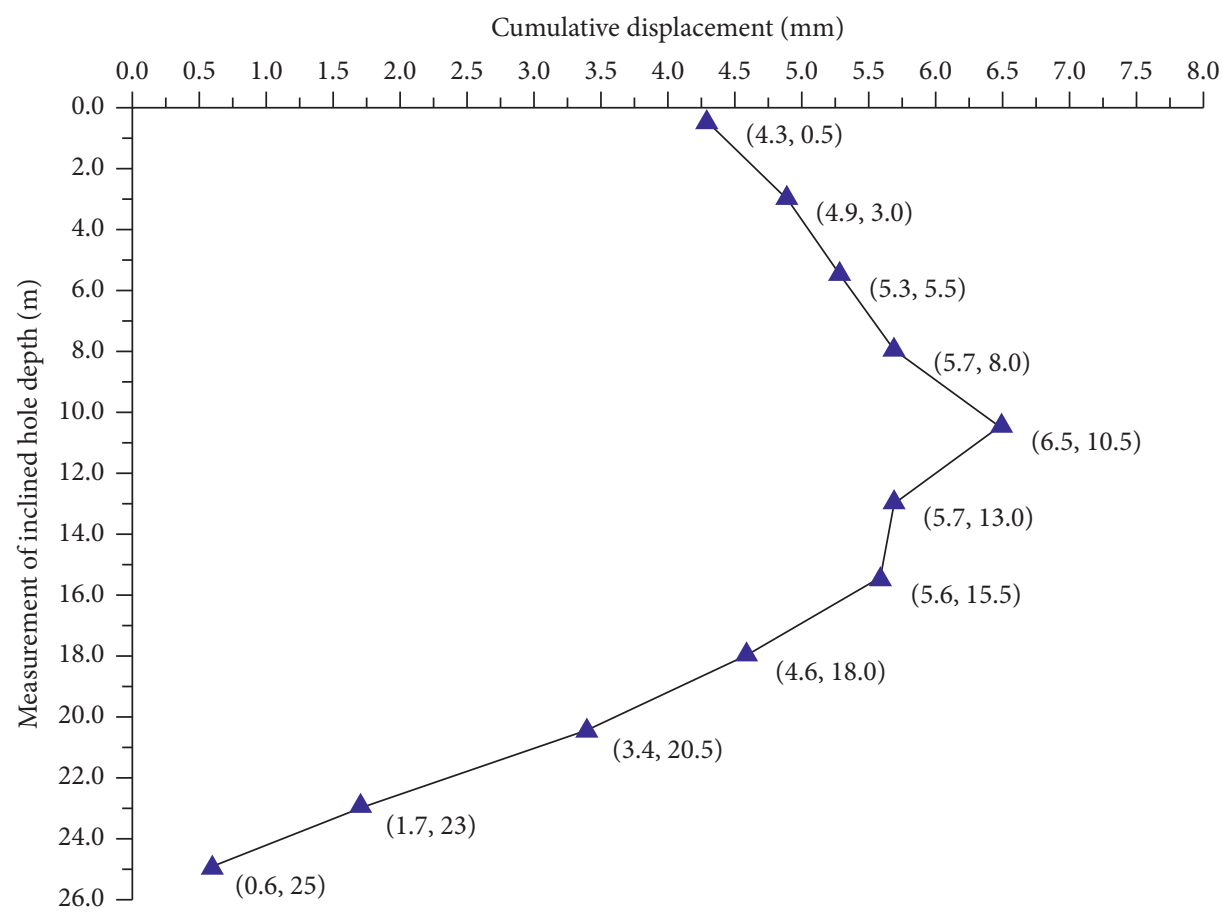

FIgURE 29: Inclinometer data when the foundation pit is excavated to the bottom.

obtained by summing up the sequence. When a singledegree-of-freedom system is subjected to a unit impulse load at any time, its dynamic response satisfies the equation:

$$
m \ddot{y}+c \dot{y}+k y=\delta(t-\tau)
$$

where $\delta(\bullet)$ is a function of Dirac $\delta$; $m$ is the mass coefficient; $c$ is the damping coefficient; and $k$ is the stiffness coefficient.

The solution of the equation is

$$
y(t)=\frac{1}{m \omega_{D}} e^{-\xi \omega_{n}(t-\tau) \sin \left[\omega_{D}(t-\tau)\right]}, \quad t \geq \tau,
$$

where $\xi$ is the damping ratio and $\omega_{D}$ is the natural frequency of the damped structure. $\omega_{D}=\omega_{n} \sqrt{1-\xi}$, where $\omega_{n}$ is the natural frequency of the undamped structure.

4.3.2. Hammering Vibration Loads of the Steel Pipe Pile. In order to make the analysis results closer to the actual construction situation, the effect of drop hammer on the 


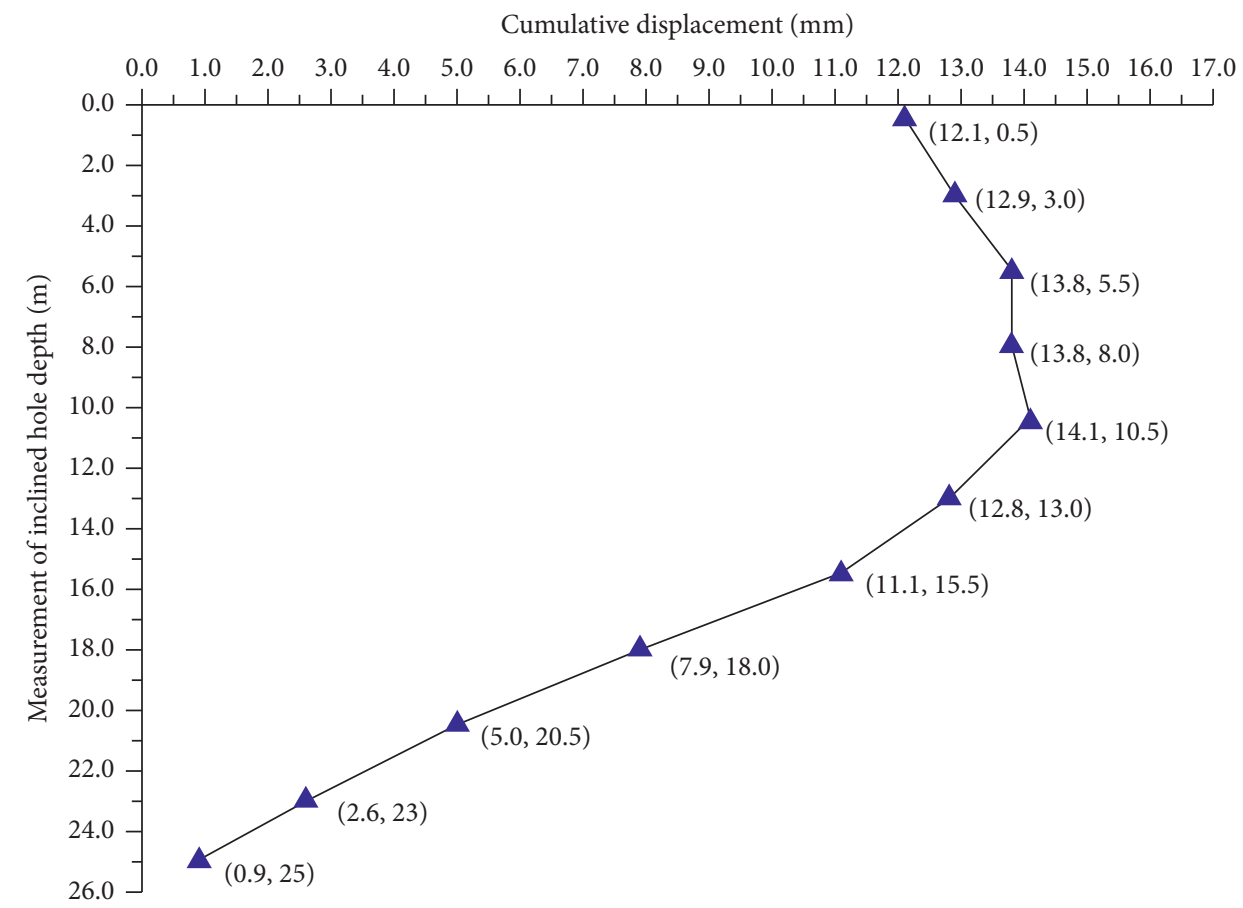

Figure 30: Inclinometer data when the wharf is excavated to the bottom.

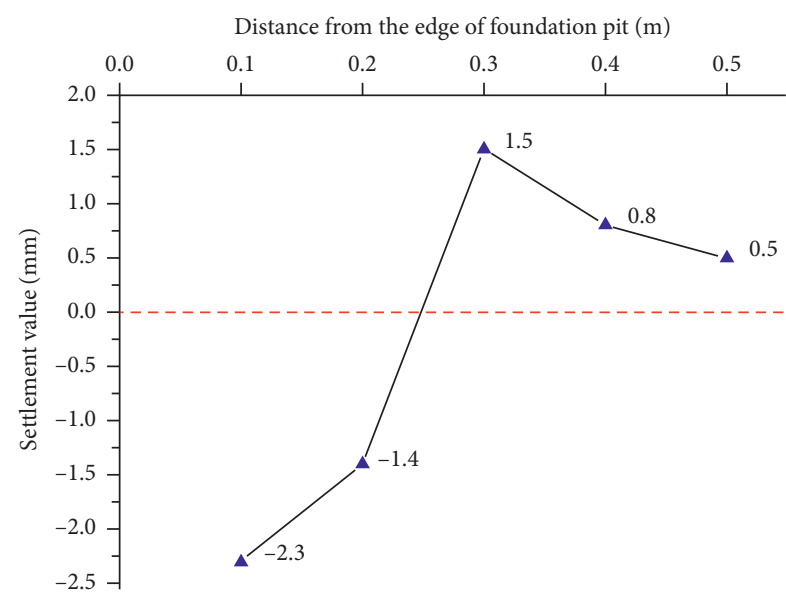

FIGURE 31: Surrounding ground settlement value when the foundation pit is excavated to the bottom.

supporting structure is taken as a triangular periodic impulse load. The model is established and the parameters of vibration load are applied considering a $600 \mathrm{~kW}$ hydraulic hammer. The hammering frequency is 30 beats per minute. The displacement boundary condition is applied to analyze the vibration.

The results are shown in Figures 21 and 22.

4.3.3. Vibro-Scouring Sand Load. In order to make the analysis results closer to the actual construction situation, the effect of vibration and sand washing on the supporting structure of the foundation pit is analyzed by static forces. Vibration and impact load is taken as ZCQ75D vibro-impact

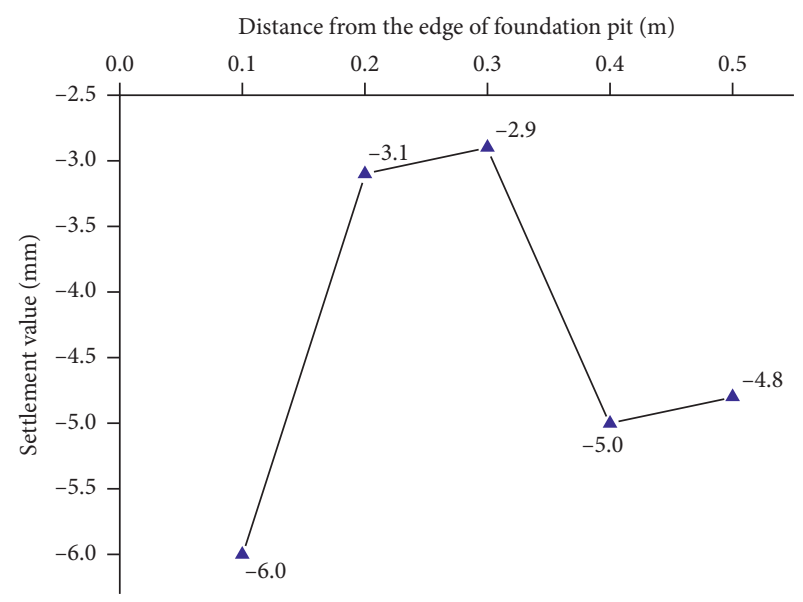

FIgURE 32: Surrounding ground settlement value when the wharf is excavated to the bottom.

hammer; the excitation force is $160 \mathrm{kN}$; the speed is $1,460 \mathrm{r} /$ $\mathrm{min}$, and the maximum depth of vibro-impact is $6.6 \mathrm{~m}$.

The results are shown in Figures 23 and 24.

4.3.4. Analysis and Summary of Dynamic Action of Wharf Construction on Supporting Structures. Through the simulation analysis of the dynamic effect of wharf construction on the supporting structure, including the hammering vibration load of steel pipe piles and the impact of sand load, the following conclusions are drawn:

(1) After the excavation of the wharf, the maximum acceleration of the supporting structure caused by 


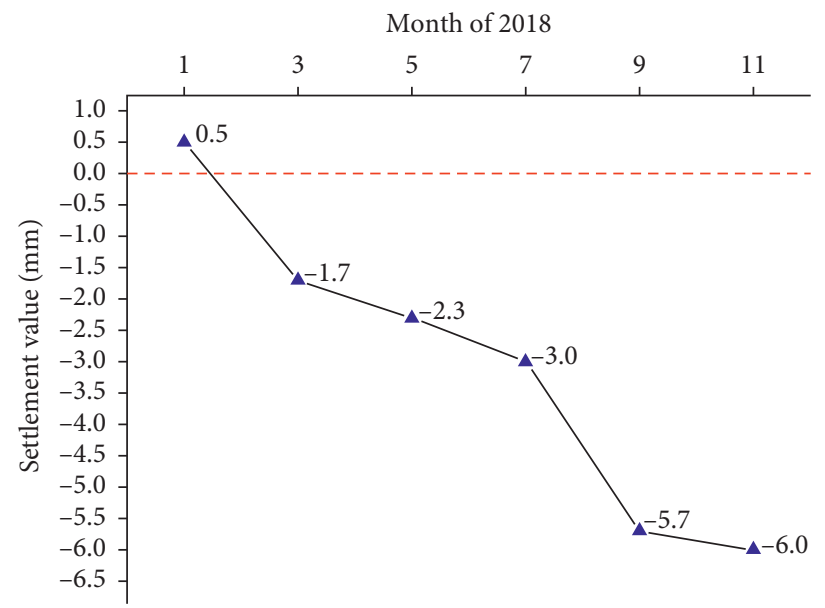

Figure 33: Ground settlement value $0.1 \mathrm{~m}$ away from the edge of the foundation pit in 2018 .

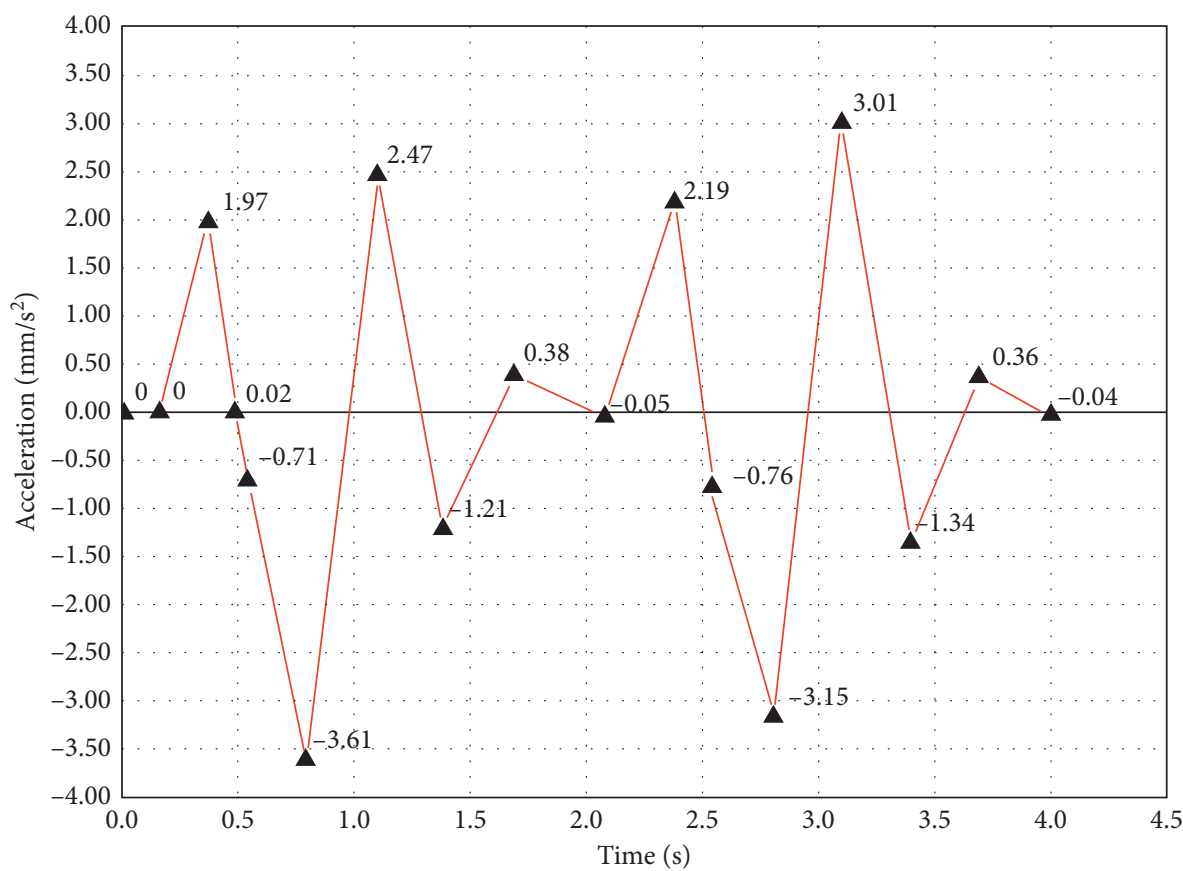

FIgURE 34: Measured acceleration at the top of the foundation pit cover near the wharf.

the vibration of a $600 \mathrm{~mm}$ steel pipe pile during construction is $3.9 \mathrm{~mm} / \mathrm{s}^{2}$.

(2) When the wharf is backfilled, the maximum acceleration of the vibration and impact of backfilled sand on the supporting structure of the foundation pit is $189 \mathrm{~mm} / \mathrm{s}^{2}$.

(3) The design basic earthquake acceleration corresponding to 6 degrees of seismic fortification intensity is $0.05 \mathrm{~g}$.

Therefore, the hammering vibration of steel pipe piles and the vibration as well as the impact of backfilling sand in the wharf have no effect on the safety of the foundation pit supporting structure.
4.4. Design and Consideration of Lattice Diaphragm Wall. In the engineering difficulties, the adverse effects caused by uncertainties in the construction of adjacent wharves are discussed. Many factors, such as waves, tides, typhoons, hydrodynamic environment, and adverse climates, as well as unbalanced loads, challenge the construction of the foundation pit support. Considering the large cantilever height of the side wall of the foundation pit caused by earthwork excavation of the wharf, it is necessary to overcome the restriction of the construction area caused by the buildings around the foundation pit (Passenger Port Station of Metro Line 4 Extension Line is located in the south of the foundation pit) and satisfy strict requirements for deformation control of the foundation pit. Based on repeated design 


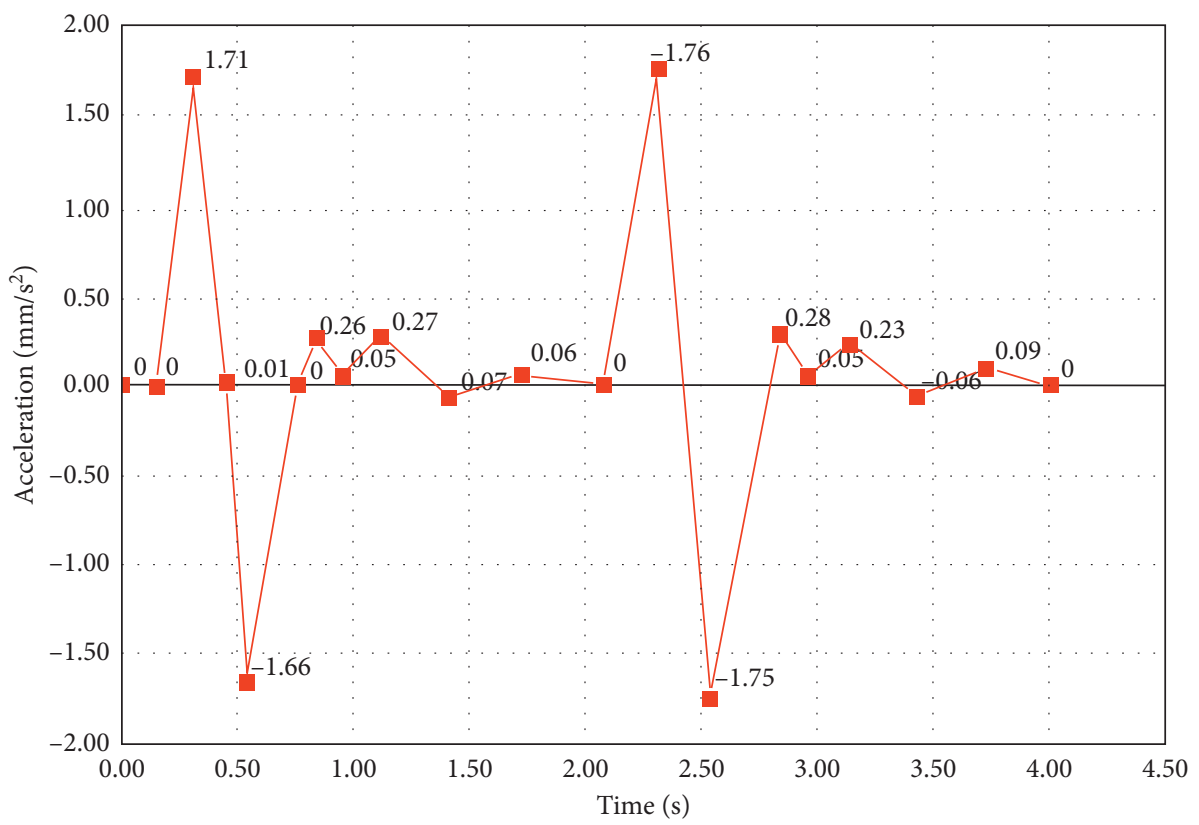

FIgURE 35: Measured ground acceleration at the pit bottom.

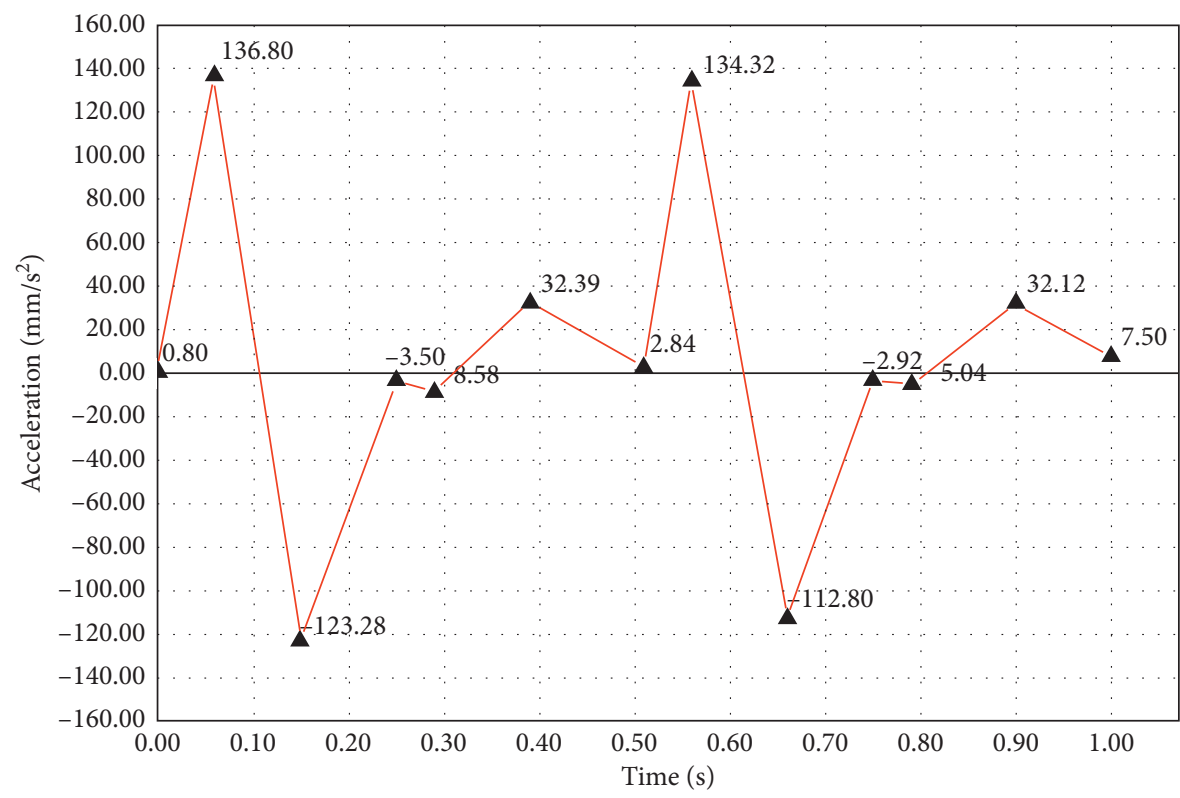

Figure 36: Measured acceleration at the top of the foundation pit cover near the wharf.

calculations, the concrete strengthening design scheme adopted is the lattice diaphragm wall for reinforcement, as shown in Figure 25. The plan layout of the foundation pit support is shown in Figure 26 and the section of support is shown in Figure 27.

\section{Analysis of Foundation Pit Monitoring Results under Critical Construction Phases}

Given that the foundation pit of this project is adjacent to the Pearl River and there are docks nearby, the situation is more complicated. Thus, the deformation of the foundation pit supporting system and surrounding environment should be monitored comprehensively, so as to realize informatization construction, capture dynamic changes of foundation pit and surrounding environment in time, ensure the safety of foundation pit supporting system, and avoid damage to the surrounding project environment. The plan layout of the foundation pit monitoring is shown in Figure 28. These monitoring items include inclination measurement of the foundation pit support (horizontal displacement of the supporting structure), foundation pit settlement, construction supporting axial force, column heave, and acceleration caused by wharf vibration. Due to space limitations, the 


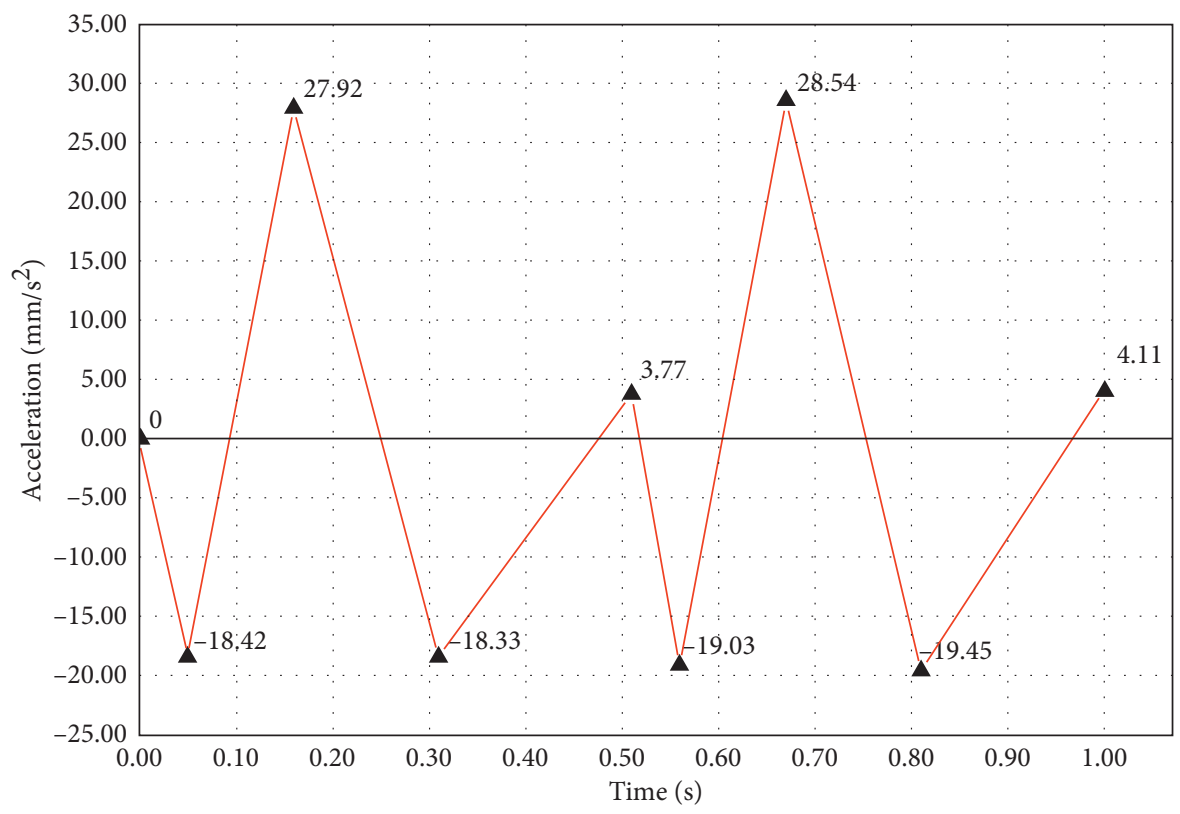

Figure 37: Measured ground acceleration at the pit bottom.

monitoring data of inclination change of the foundation pit support (horizontal displacement of the supporting structure), foundation pit settlement, and acceleration caused by wharf vibration are analyzed in the following part.

\subsection{Analysis of Inclinometer Monitoring of the Foundation Pit} Supporting Structure. The foundation pit was excavated to the bottom in May 2018, and the wharf was excavated to the bottom in November 2018. The monitoring data of the inclinometer tube on the construction site near the wharf were taken for analysis. The maximum horizontal displacement of the foundation pit supporting structure is $6.5 \mathrm{~mm}$ when foundation pit excavation ends, and the maximum horizontal displacement of the foundation pit supporting structure is $14.1 \mathrm{~mm}$ when wharf excavation ends.

According to the results of numerical simulation analysis, the maximum horizontal displacement of the retaining structure is $38.18 \mathrm{~mm}$ when the foundation pit is excavated first and the wharf is excavated afterwards. The maximum value of the actual monitoring result of horizontal displacement of the supporting structure is $14.1 \mathrm{~mm}$, which is far less than the analytical value and within the safety range. It can fully guarantee the safety of the whole process of the foundation pit construction.

The monitoring data of inclination measurement for foundation pit support are shown in Figures 29 and 30.

5.2. Analysis of Foundation Pit Settlement. Figure 31 shows that when the foundation pit is excavated to the bottom, the maximum settlement of the ground around the foundation pit is $2.3 \mathrm{~mm}$. It can be seen from Figure 32 that when the wharf is excavated to the bottom, the maximum settlement of the ground around the foundation pit is $6.0 \mathrm{~mm}$. During the foundation pit construction (2018), the change of ground settlement around $0.1 \mathrm{~m}$ away from the edge of the foundation pit is shown in Figure 33.

The maximum settlement value of the ground around the foundation pit is far less than the specified safety range (less than or equal to $30 \mathrm{~mm}$ ), which can fully ensure the safe construction of the project.

\subsection{Analysis of Acceleration Caused by Wharf Vibration}

5.3.1. Acceleration Monitoring Value Caused by Hammer Vibration of Steel Pipe Piles. The acceleration caused by the vibration of steel pipe piles on the cover plate measured near the wharf of the foundation pit is shown in Figure 34. The maximum acceleration actually monitored on the cover plate of the foundation pit is $3.01 \mathrm{~mm} / \mathrm{s}^{2}, 24 \%$ less than the maximum $3.96 \mathrm{~mm} / \mathrm{s}^{2}$ obtained by the numerical simulation analysis. The acceleration caused by steel pipe pile vibration on the foundation pit bottom is shown in Figure 35. The actual monitored maximum acceleration on the foundation pit bottom is $1.76 \mathrm{~mm} / \mathrm{s}^{2}, 18 \%$ smaller than the maximum $2.14 \mathrm{~mm} / \mathrm{s}^{2}$ obtained by the numerical simulation analysis. Both accelerations are within the safety range $(0.5 \mathrm{~g}$ or $490 \mathrm{~mm} / \mathrm{s}^{2}$ ), which can ensure that the vibration of steel pipe piles will not cause damage to the foundation pit.

\subsubsection{Acceleration Monitoring Value Generated by Vibrating} Sand Impact. The acceleration generated by vibrating sand's vibration on the cover plate measured near the foundation pit wharf is shown in Figure 36. The actual monitored maximum acceleration of the cover plate of the foundation pit is $136.80 \mathrm{~mm} / \mathrm{s}^{2}, 28 \%$ smaller than the maximum value of $189.35 \mathrm{~mm} / \mathrm{s}^{2}$ obtained by the numerical simulation analysis. The acceleration generated by vibrating sand's vibration on the foundation pit bottom is 
shown in Figure 37. The actual monitored maximum acceleration on the foundation pit bottom is $28.54 \mathrm{~mm} / \mathrm{s}^{2}$, $22 \%$ smaller than the maximum value of $36.42 \mathrm{~mm} / \mathrm{s}^{2}$ obtained by the numerical simulation analysis. Both accelerations are within a safety range $\left(0.5 \mathrm{~g}\right.$ or $\left.490 \mathrm{~mm} / \mathrm{s}^{2}\right)$ to ensure that the vibration from vibrating sand will not cause damage to the foundation pit.

\section{Conclusions}

In view of various complex situations such as wave tides and vibration loads existing in the offshore foundation pit, this paper analyzes and studies the actual project in combination with the theory. The obtained results could promote the further development of the research on the influence law of wave water power and vibration loads on the supporting structure and soil mass. Thus, this paper provides a reference for the supporting engineering of the foundation pit in the deep soft soil area of the wharf near the sea, mainly including the following:

(1) Hydraulic action of waves, tides, and extreme weather effects of super typhoons causes dynamic changes of water levels on the side of the offshore foundation pit; thus, it results in asymmetric loads on both sides of the foundation pit supporting structure. The supporting structure of the lattice diaphragm wall, i.e., diaphragm wall supported by the concrete slab, is adopted. The size of the supporting structure is determined by the specific analysis results. The problem of the asymmetric load caused by waves, tides, and extreme weather (e.g., super typhoons) is successfully solved. The successful implementation of the foundation pit validates the applicability of the technology.

(2) Due to the vibration load that may be caused by the surrounding construction of the offshore foundation pit, a dynamic analysis of the supporting structure is conducted in this paper based on the theory of structural dynamics to obtain the dynamic response under extreme conditions. A dynamic design of the supporting structure is also conducted under adverse conditions caused by the surrounding construction. With this, the applicability of the dynamic analysis theory of the supporting structure is verified.

(3) The maximum horizontal displacement of the side wall is $6.5 \mathrm{~mm}$ when the foundation pit is excavated to the end and is $14.1 \mathrm{~mm}$ when the adjacent wharf is excavated to the end. It can be seen that the displacement caused by the excavation of the adjacent wharf is $7.6 \mathrm{~mm}$, which exceeds the horizontal displacement caused by the excavation of the foundation pit itself. Therefore, in similar foundation pit projects, attention should be paid to the surrounding construction; the degree of influence should be determined by the scale of the adjacent construction, and the supporting scheme and parameters should be adjusted to ensure the safe implementation of the project.

\section{Data Availability}

The data used to support the findings of this study are included within the article.

\section{Conflicts of Interest}

The authors declare that there are no conflicts of interest regarding the publication of this paper.

\section{Acknowledgments}

The authors gratefully acknowledge the financial support provided by the National Natural Science Foundation of China (nos. 41702295 and 41827807) and Special Fund for Science and Technology Innovation Strategy of Guangdong Province (Natural Science Foundation of Basic and Applied Basic Research Foundation of Guangdong Province).

\section{References}

[1] T. Y. Wu, W. L. Qiu, and G. R. Wu, "Fatigue damage evaluation of pile-supported bridges under stochastic ice loads," Advances in Civil Engineering, vol. 2020, Article ID 1853963, pp. 1-14, 2020.

[2] B. W. Byrne, G. T. Houlsby, H. J. Burd et al., "PISA design model for monopiles for offshore wind turbines: application to a stiff glacial clay till," Géotechnique, pp. 1-18, 2020.

[3] H. J. Burd, D. M. Taborda, L. Zdravković et al., "PISA design model for monopiles for offshore wind turbines: application to a marine sand," Géotechnique, pp. 1-19, 2020.

[4] A. Mehmanparast, J. Taylor, F. Brennan, and I. Tavares, "Experimental investigation of mechanical and fracture properties of offshore wind monopile weldments: SLIC interlaboratory test results," Fatigue \& Fracture of Engineering Materials \& Structures, vol. 41, no. 12, pp. 2485-2501, 2018.

[5] A. Mehmanparast, F. Brennan, and I. Tavares, "Fatigue crack growth rates for offshore wind monopile weldments in air and seawater: SLIC inter-laboratory test results," Materials \& Design, vol. 114, pp. 494-504, 2017.

[6] B. Y. Dagli, Y. Tuskan, and U. Gokkus, "Evaluation of offshore wind turbine tower dynamics with numerical analysis," Advances in Civil Engineering, vol. 2018, Article ID 3054851, pp. 1-11, 2018.

[7] M. F. Lei, L. H. Liu, Y. X. Lin, and J. Li, "Study on flexural bearing capacity calculation method of enclosure pile with partial excision in deep foundation pit," Advances in Civil Engineering, vol. 2019, Article ID 4812857, pp. 1-10, 2019.

[8] J. K. Sun, S. P. Wang, X. J. Shi, F. Wu, and L. Y. Zeng, "Study on the design method for the deformation state control of pile-anchor structures in deep foundation pits," Advances in Civil Engineering, vol. 2019, Article ID 9641674, pp. 1-16, 2019.

[9] X. S. Zhang, X. C. Zhang, and Y. S. Han, "A case study on field monitoring analysis of deep foundation pit in soft soils," Advances in Civil Engineering, vol. 2019, Article ID 9342341, pp. 1-10, 2019.

[10] S.-C. Li, C. Xie, Y.-H. Liang, and Q. Yan, "Seepage flow model and deformation properties of coastal deep foundation pit under tidal influence," Mathematical Problems in Engineering, vol. 2018, Article ID 9714901, pp. 1-10, 2018.

[11] J. Qin, W. Lu, R. W. Wang, and P. S. Gao, "Structural design of a deep foundation pit in the coastal soft soil region of China," 
WIT Transactions on the Built Environment, vol. 140, pp. 339-344, 2013.

[12] J. X. Yang, W. S. Hou, C. M. Zheng, Z. H. Wang, and $\mathrm{X}$. Zhang, "Application of linked piles in deep foundation pit in a coastal area," Chinese Journal of Geotechnical Engineering, vol. 32, no. 1, pp. 207-209, 2010, in Chinese.

[13] L. Zhang and W. Xiao, "Responses of excavation base under influences of confined aquifer: an analytical approach," Marine Georesources \& Geotechnology, vol. 2019, Article ID 1695028, pp. 1-14, 2019.

[14] Y. Hong and C. W. W. Ng, "Base stability of multi-propped excavations in soft clay subjected to hydraulic uplift," $\mathrm{Ca}$ nadian Geotechnical Journal, vol. 50, no. 2, pp. 153-164, 2013.

[15] Y. Hong, C. W. W. Ng, G. B. Liu, and T. Liu, "Three-dimensional deformation behaviour of a multi-propped excavation at a "greenfield" site at Shanghai soft clay," Tunnelling and Underground Space Technology, vol. 45, pp. 249-259, 2015.

[16] P. L. A. Barros and P. J. Santos, "Coefficients of active earth pressure with seepage effectficients of active earth pressure with seepage effect," Canadian Geotechnical Journal, vol. 49, no. 6, pp. 651-658, 2012.

[17] H. W. Ying, W. Sun, and W. Zhong, “Over-pore pressure response test of offshore foundation pit under wave action research," Chinese Journal of Rock and Soil Mechanics, vol. 37, no. 2, pp. 187-194, 2016, in Chinese.

[18] S. L. Guo, C. H. Yan, L. C. Yu, and Y. You, "Design of the supporting structures for large and unusually shaped foundation pit near the Yangtze river," Advances in Civil Engineering, vol. 2020, Article ID 3831805, pp. 1-9, 2020.

[19] Y. Wu, H. Yamamoto, J. Cui, and H. Chen, "Influence of load mode on particle crushing characteristics of silica sand at high stresses," International Journal of Geomechanics, vol. 20, no. 3, Article ID 04019194, pp. 1-14, 2020.

[20] H. G. Di, H. J. Guo, S. H. Zhou, J. M. Chen, and L. Wen, "Investigation of the axial force compensation and deformation control effect of servo steel struts in a deep foundation pit excavation in soft clay," Advances in Civil Engineering, vol. 2019, Article ID 5476354, pp. 1-16, 2019. 